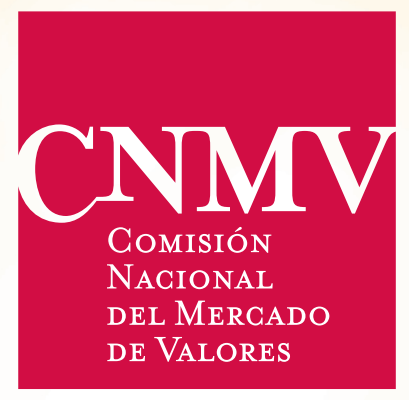

\title{
A New Test of Statistical Arbitrage with Applications to Credit Derivatives Markets
}

Sergio Mayordomo CNMV

Juan Ignacion Peña

Universidad Carlos III de Madrid

Juan Romo

Universidad Carlos III de Madrid

Documentos de Trabajo

No 47 



\title{
A New Test of Statistical Arbitrage with Applications to Credit Derivatives Markets
}

\author{
Sergio Mayordomo \\ Department of Research and Statistics \\ Comisión Nacional del Mercado de Valores (CNMV)
}

Juan Ignacio Peña

Department of Business Administration

Universidad Carlos III de Madrid

Juan Romo

Department of Statistics

Universidad Carlos III de Madrid

\author{
Documentos de Trabajo \\ N ${ }^{\circ} 47$
}

Junio/June 2011

The authors acknowledge Óscar Arce, Max Bruche, Álvaro Cartea, Antonio Díez de los Ríos, Abel Elizalde, Javier Gil-Bazo, Oliver Linton, Beatriz Mariano, David Moreno, José Penalva, Joaquín Poblet, María Rodríguez-Moreno, Eduardo Schwartz, Jesús Saurina, Pedro Serrano, Javier Suárez, Antoni Vaello, and seminar participants at Carlos III University, CNMV, University of Navarra, University of Cambridge, Universitat de les Illes Balears, XVI Foro de Finanzas, XXXIII Symposium of Economic Analysis, 2010 Financial Management Association (FMA) European Conference, and 2010 European Financial Management Association (EFMA) Annual Meeting for all their comments and suggestions. Sergio Mayordomo and Juan Ignacio Peña acknowledge financial support from MICINN Grant Ref: ECO2009-12551. Juan Romo acknowledges financial support from MICINN Grant Ref: ECO2008-05080. A previous version of this paper circulated under the title "Are There Arbitrage Opportunities in Credit Derivatives Markets? A New Test and an Application to the Case of CDS and ASPs". Any errors and omissions are the responsibility of the authors. 
The opinions in this Working Paper are the sole responsibility of the authors and they do not necessarily coincide with those of the CNMV.

The CNMV publishes this Working Paper Series to spread research in order to contribute to the best knowledge of the stock markets and their regulation.

The CNMV distributes its reports and publications via the Internet at www.cnmv.es

(C) CNMV. The contents of this publication may be reproduced, subject to attribution.

Las opiniones expresadas en este documento reflejan exclusivamente el criterio de los autores y no deben ser atribuidas a la Comisión Nacional del Mercado de Valores.

La Comisión Nacional del Mercado de Valores, al publicar esta serie, pretende facilitar la difusión de estudios que contribuyan al mejor conocimiento de los mercados de valores y su regulación.

La Comisión Nacional del Mercado de Valores difunde la mayoría de sus publicaciones a través de la red Internet en la dirección www.cnmv.es

(C) CNMV. Se autoriza la reproducción de los contenidos de esta publicación siempre que se mencione su procedencia.

ISSN (edición impresa): 2172-6337

ISSN (edición electrónica): 2172-7147

Depósito Legal: BI-2910-2010

Maqueta e imprime: Composiciones Rali, S.A. 


\section{Abstract}

This paper presents a new statistical arbitrage test which has lower Type I error and selects arbitrage opportunities with lower downside risk than existing alternatives. The test is applied to credit derivatives markets using strategies combining Credit Default Swaps and Asset Swaps. Using four different databases (GFI, Reuters, CMA and JP Morgan) from 2005 to 2009, we find persistent mispricings before and during the current financial crisis. However, after considering funding and trading costs, these mispricings are unlikely to provide profitable arbitrage opportunities.

Keywords: Persistent Mispricings, Credit Derivatives, Credit Spreads, Subsampling.

JEL classification codes: C12, G12, G14. 



\section{Table of contents}

2.1 Definition

2.3 Hypothesis testing

2.4 Statistical arbitrage tests

3 A new test of statistical arbitrage

$4 \quad$ Empirical Application $\quad 23$

\begin{tabular}{llr}
\hline $4.1 \quad$ Cash-and-carry arbitrage strategy & 23
\end{tabular}

\begin{tabular}{llr}
\hline 4.2 Data & 26
\end{tabular}

\begin{tabular}{ll}
4.2 Data & 26 \\
\hline
\end{tabular}

\begin{tabular}{llr}
\hline 4.3 & Results & 33
\end{tabular}

\begin{tabular}{llr}
\hline $4.4 \quad$ Robustness tests and extensions & 41 \\
\hline
\end{tabular}

5 Conclusions $\quad 45$ 
Index of figures

\section{Index of tables}

\begin{tabular}{llr} 
TABLE 1 & MPR and JTTW tests' Type I Errors Analysis & 21 \\
\hline TABLE 2 & Descriptive Statistics & 29 \\
\hline TABLE 3 & Statistical Arbitrage Test for Unconstrained Mean (UM) model & 35 \\
\hline TABLE 4 & Understanding the Persistent Mispricings & 40 \\
\hline
\end{tabular}




\section{Introduction}

Statistical arbitrage represents a zero cost, self-financing trading opportunity that has positive expected cumulative trading profits with a declining time-averaged variance and a probability of loss that converges to zero. The statistical arbitrage analysis is designed to exploit persistent anomalies and was firstly introduced by Hogan, Jarrow, Teo, and Warachka (2004) (HJTW henceforth) and later improved in Jarrow, Teo, Tse, and Warachka (2007) (JTTW henceforth). They test statistical arbitrage on stock markets. HJTW analyzes momentum and value trading strategies while JTTW extends the analysis to stock liquidity and industry momentum strategies. Both studies find that these strategies generate statistical arbitrage opportunities even after adjusting for market frictions such as transaction costs, margin requirements, liquidity buffers for the marking-to-market of short-sales and borrowing rates, although momentum and value strategies offer the most profitable trading opportunities. In this paper we present a new statistical arbitrage test with enhanced testing characteristics. We then apply the test to analyze investment strategies in credit derivatives markets. The investment strategy to be analyzed is the equivalence relation between the credit spreads obtained from the Credit Default Swap (CDS) and the Asset Swap Package (ASP). The strategy is based on the equivalence relation arising from a cash-and-carry strategy in which a given investor trades two self-financing portfolios based in credit derivatives. The first portfolio contains a long position in a CDS while the second contains a long position in an ASP funded at Euribor. It can be shown that this second portfolio is equivalent to a synthetic short position in a CDS. For this reason, there should be an equivalence relation between the payoffs of both portfolios, which are given by the CDS premium and the asset swap spread, respectively.

The analysis of the equivalence relation between credit spreads has been traditionally done on the basis of the cointegration test proposed by Engle and Granger (1987). Given that the credit spreads price credit risk, one expects any pair of equivalent credit spreads to be closely linked in the long-run. Blanco, Brennan, and Marsh (2005) analyze this equivalence relation for CDS and bond spreads and find support, in general, for the parity relation as a long-run equilibrium condition. Zhu (2006), in a similar study, finds similar results and also analyzes the determinants of the basis, defined as the difference between the CDS and bond spreads. He finds that both spreads respond differently to credit conditions such as rating events. Trapp (2009) analyzes trading opportunities that arise from differences between the bond and the CDS market and show that the basis size is closely related to measures of company-specific credit risk and liquidity, and to market conditions. De Wit (2006) analyzes the basis calculated as the difference between par ASP and CDS spreads and applies a cointegration test to show that the basis is usually stationary. In fact, ASP spreads should be a more accurate measure of credit risk than bond spreads. This idea is supported by De Wit (2006), Felsenheimer (2004), Francis, Kakodkar, and Martin (2003), and Mayordomo, Peña, and Romo (2011) among others. 
HJTW and JTTW tests are based on the behavior of the increment in cumulative trading profits associated with the corresponding strategies. In both studies, innovations are assumed to be weakly dependent and stationary. Therefore, JTTW use a stationary bootstrap methodology to compute the test statistic's empirical distribution. Stationarity is a very convenient assumption but also a restrictive one when modeling financial time series. Just as it is also restrictive to treat the errors in any empirical econometric work as homoskedastic.

Our paper contributes to the literature in four dimensions. The first contribution of our paper is to present a new test that allows for nonstationarity in incremental trading profits series and also for nonnormal, autocorrelated, heteroskedastic and possibly nonstationary innovations. This new test is based on the subsampling methodology introduced in Politis, Romano, and Wolf (1995) and (1997) and extended in Politis, Romano, and Wolf (1999a, 1999b) and (2001). This technique is based on asymptotic inference and provides an asymptotically valid test under weak assumptions. Extensive simulation exercises suggest that our test has lower Type I error (false positive) and chooses potential arbitrage opportunities with lower downside risk than existing alternatives.

Our second contribution relates to the appropriate way of testing for the existence of mispricings. The analysis of the equivalence relation between credit spreads has been traditionally done on the basis of the cointegration test. The validity of the cointegration methodology to analyze the mispricings is based on the assumption that bonds/ASPs can be shorted to guarantee that the equivalence relation holds. Nevertheless, according to Schonbucher (2003) and Mengle (2007) shorting a corporate bond or ASP with a required maturity, even years, is not always a feasible option. ${ }^{1}$ It implies that traders might not be able to exploit deviations in the equivalence relation when the CDS premium is higher than the asset swap spread and so, ASP short sales are necessary. This asymmetry could affect the dynamic adjustment of credit spreads. A cointegration test as the one employed in Blanco, Brennan, and Marsh (2005) cannot isolate by itself strategies in which an ASP short sale is involved because it is based on both types of deviations from the equivalence relation. However, a statistical arbitrage test allows us to study the existence of statistical arbitrage whenever only long positions in ASPs are needed. Moreover, the new statistical arbitrage methodology overcomes two problems that arise from the use of the cointegration analysis and that this methodology ignores (i) bonds or ASPs short sales restrictions and (ii) the actual risk incurred to obtain arbitrage profits. Hence, due to the complications associated with ASPs or bonds short positions and due to the potential high costs of going short in ASPs, we first focus our analysis to testing the cases in which only long positions in CDSs and ASPs are needed. Additionally, and for the sake of completeness, we extend the study to test the strategies that are based on bonds or ASPs short-positions.

1 The short sale of bonds or ASPs could be done via a repurchase agreement (repo) but as Blanco, Brennan, and Marsh (2005) explain, it is impossible to borrow a bond via a repo. The reason is that repo market for corporate bonds is illiquid and even if it were possible to short a bond via a repo, the tenor of the agreement would be short. Schonbucher (2003) states that this limitation could be solved by issuing creditlinked notes linked to the corresponding bond and selling them to the investors in the asset swap market. This alternative presents other limitations given that the issuance of credit-linked notes takes time and implies high fixed costs. 
Other arbitrage strategies in fixed income markets such as swap spread arbitrage, yield curve arbitrage, mortgage arbitrage, volatility arbitrage and capital structure arbitrage are addressed in Duarte, Longstaff, and Yu (2007). They find that all the five previous strategies yield positive excess returns which are positively skewed. On the basis of these results, they suggest that there could be more economic substance to fixed income arbitrage than simply picking up nickels in front of a steamroller. Capital structure arbitrage is usually based on strategies trading equity instruments against CDSs. Yu (2005), Bajlum and Larsen (2007), and Cserna and Imbierowicz (2008) find significant positive capital structure arbitrage returns. Jarrow, Li, and Ye (2009) explore arbitrage opportunities in the term structure of CDS spreads and point out potential for arbitrage in this term structure in the basis of the Sharpe ratios obtained. However, to the best of our knowledge, ours is the first paper that applies the statistical arbitrage methodology to study the relation between two credit derivatives (CDSs and ASPs) whose spreads, or prices for credit risk, should be similar. ${ }^{2}$ The use of asset swap spreads should allow a more precise analysis of the parity relation between CDS and bond spreads. This is our third contribution.

To take into account the effects of the ongoing financial crisis, we analyze two different subsamples which cover the periods before and during the subprime crisis. It should be emphasized that our test is only applied to the days when there is a minimum of trading activity. The results suggest that the mispricings observed before and during the crisis are unlikely to provide profitable arbitrage opportunities once realistic assessments of the funding and trading costs are included. This is our fourth contribution.

Using four different CDS databases (GFI, CMA, Reuters, and J.P. Morgan) and a sample of 55 cases, which correspond to the same number of bonds, that spans from November 2005 to August 2007, we find 27 persistent mispricings in which the bases are persistently negative using the methodology of HJTW and JTTW. A persistent negative basis implies that the CDS spreads are too low in comparison with asset swap spreads. The new test finds 16 persistent negative bases. Employing a sample of 46 cases which covers the crisis period and spans from August 2007 to June 2009, we find eight persistent negative bases with the new test. Employing HJTW and JTTW methodology, we find 11 mispricings. We find that arbitrageurs engaging in arbitrage opportunities detected by JTTW's test (but not detected by our test) are exposed to significant downside risk that is even more extreme during the crisis period. Thus, there is an economically relevant difference between JTTW's test and our test besides its better statistical properties. After considering funding and trading costs, we do not find profitable arbitrage opportunities in any of the two subperiods. As far as we know, ours is the first paper showing formally the effect of the trading and funding costs in arbitrage opportunities in credit markets and more especially, the effect of their increase due to the credit squeeze of the recent financial crisis.

The paper is divided into five sections. In Section 2 we address the concept of statistical arbitrage and its implementation. In Section 3 we introduce the new test. Section 4 includes the empirical application of the new test and Section 5 concludes the paper.

$2 \mathrm{Yu}$ (2006) uses the HJTW procedure to detect statistical arbitrage in monthly capital structure arbitrage returns generated with CDS and stock price data. 



\section{Statistical arbitrage}

\subsection{Definition}

Following JTTW's definition, statistical arbitrage is a zero initial cost, self-financing trading strategy with a cumulative discounted trading profits $v(t)$ such that:

(i) $v(0)=0$

(ii) $\lim _{t \rightarrow \infty} E^{P}[v(t)]>0$

(iii) $\lim _{t \rightarrow \infty} P(v(t)<0)=0$, and

(iv) $\lim _{t \rightarrow \infty} \operatorname{Var}[\Delta v(t) \mid \Delta v(t)<0]=0$

Statistical arbitrage requires that the expected cumulative discounted profits, $v(t)$, are positive, the probability of loss converges to zero and the variance of the incremental trading profits $\Delta v(t)$ also converges to zero. The fourth condition suggests that investors are only concerned about the variance of a potential decrease in wealth. Whenever the incremental trading profits are nonnegative, their variability is not penalized. In other words, and as JTTW state, this condition avoids penalizing positive profits deviations from their expected values, given that investors benefit from these deviations. A statistical arbitrage opportunity implies that the amount invested in the risk-free asset becomes more important over time than the daily investments.

Although statistical arbitrage is defined over an infinite time horizon, there is a finite timepoint $t^{*}$, such that the probability of a loss is arbitrarily small, $P\left(v\left(t^{*}\right)<0\right)=\mathcal{E}$. Standard arbitrage is a special case of statistical arbitrage with a zero cost trading strategy that offers the possibility of a gain with no possibility of a loss. Hence, the probability of a loss should be equal to zero at the timepoint $t^{*}, P\left(v\left(t^{*}\right)<0\right)=0$. Thus, statistical arbitrage converges to standard arbitrage in the limit (as $t$ tends to infinity).

It is important to emphasize that albeit statistical arbitrage is a procedure suitable for long run investment periods, investors can benefit from statistical arbitrage in shorter time horizons. For instance, Bondarenko (2003) apply statistical arbitrage methods to index futures options and finds that selling unhedged put options one month before maturity would have resulted in high and statistically significant average excess returns. Investors with finite time horizon (in our empirical application this horizon is two years) view statistical arbitrage opportunities as remarkably attractive as they offer positive expected discounted profits, variance that becomes arbitrary small, and decreasing risk of a loss. 


\subsection{Implementation}

The methodology for analyzing the existence of a statistical arbitrage opportunity is based on HJTW, later improved in JTTW. This methodology is based on the incremental discounted cumulative trading profits $\Delta v_{i}$ measured at equidistant time points. Firstly, we employ a process denoted as the unconstrained mean (UM) model where $\Delta v_{i}$ is assumed to evolve over time as:

$$
\Delta v_{i}=\mu i^{\theta}+\sigma i^{\lambda} z_{i}
$$

for $i=1,2, \ldots, n$ where $z_{i}$ are the innovations such that $z_{0}=0$ and so, both $v\left(t_{0}\right)$ and $\Delta v_{0}$ are zero. Parameters $\theta$ and $\lambda$ indicate whether the expected trading profits and the volatility, respectively, are decreasing or increasing over time and their intensity. Under the assumption that innovations $z_{i}$ are i.i.d. $N(0,1)$ random variables, the expectation and variance of the discounted incremental trading profits in equation (2) are $E\left[\Delta v_{i}\right]=\mu i^{\theta}$ and $\operatorname{Var}\left[\Delta v_{i}\right]=\sigma^{2} i^{2 \lambda}$.

The discounted cumulative trading profits generated by a given strategy are:

$$
v\left(t_{n}\right)=\sum_{i=1}^{n} \Delta v_{i} \sim N\left(\mu \sum_{i=1}^{n} i^{\theta}, \sigma^{2} \sum_{i=1}^{n} i^{2 \lambda}\right)
$$

while the log likelihood function for the increments in equation $(2)$ is:

$$
\log L\left(\mu, \sigma^{2}, \lambda, \theta \mid \Delta v\right)=-\frac{1}{2} \sum_{i=1}^{n} \log \left(\sigma^{2} i^{2 \lambda}\right)-\frac{1}{2 \sigma^{2}} \sum_{i=1}^{n} \frac{1}{i^{2 \lambda}}\left(\Delta v_{i}-\mu i^{\theta}\right)^{2}
$$

The parameters are estimated by maximizing the previous log likelihood function from a nonlinear optimization method based on a Quasi-Newton-type algorithm.

The cash-and-carry strategy generates statistical arbitrage opportunities if incremental trading profits satisfy simultaneously the following hypotheses:

$\mathrm{H} 1 \quad \mu>0$,

$\mathrm{H} 2 \quad \lambda<0$ or $\theta>\lambda$

H3 $\theta>\max \left\{\lambda-\frac{1}{2},-1\right\}$

The first hypothesis is due to the second property of statistical arbitrage which requires that the expectation of the discounted cumulative trading profits is positive. The second hypothesis is obtained from the fourth property and ensures that the variance of the incremental trading profits, given a potential drop in them, converges to zero. The third hypothesis involves the trend in expected profits and the trend in volatility and its expression comes from the convergence of $P(v(t)<0)$ to zero. It ensures that any potential decline in expected trading profits do not prevent convergence to arbitrage.

As in JTTW, a more restrictive version of model (2) is also employed in the analysis. It is based on constant expected profits over time and it implies that the parameter $\theta$ is set to zero. This model is defined as the constrained mean(CM) model. Under this assumption, the process for the evolution of the incremental trading profits is: 


$$
\Delta v_{i}=\mu+\sigma i^{\lambda} z_{i}
$$

And the required hypotheses to be satisfied for the existence of statistical arbitrage opportunities are:

H1 $\mu>0$,

H2 $\lambda<0$.

\subsection{Hypothesis testing}

Under the assumption that the trading profits evolve as a UM model, all the following restrictions must be satisfied simultaneously in order to provide a statistical arbitrage opportunity:

$R_{1}: \quad \mu>0$ and

$R_{2}: \quad \lambda<0$ or $\theta-\lambda>0$, and

$R_{3}: \quad \theta-\lambda+\frac{1}{2}>0$ and

$R_{4}: \quad \theta+1>0$

Nevertheless, if the trading profits evolve as a CM model (5) the restrictions to be satisfied simultaneously become:

$R_{1}: \quad \mu>0$ and

$R_{2}: \lambda<0$

The existence of statistical arbitrage is thus based on an intersection of subhypothesis. On the other hand, the absence of statistical arbitrage is based on a union of four subhypotheses which are given by the complementary of the previous four hypotheses. We set the null hypothesis as the absence of statistical arbitrage and then, the restrictions for the UM model become:

$R_{1}^{c .} \quad \mu \leq 0$ or

$R_{2}^{c}: \quad \lambda \geq 0$ and $\theta-\lambda \leq 0$, or

$R_{3}^{c .} \quad \theta-\lambda+\frac{1}{2} \leq 0$ or

$R_{4}^{c .} \quad \theta+1 \leq 0$.

While for the CM model the restrictions are:

$R_{1}^{c .} \quad \mu \leq 0$ or

$R_{2}^{c .} \quad \lambda \geq 0$. 
If one of the previous restrictions is satisfied, we conclude that no statistical arbitrage opportunities exist.

\subsection{Statistical arbitrage tests}

The results obtained by HJTW could be influenced by the limitations of the Bonferroni approach employed in the paper. Their test presents a low statistical power to reject an incorrect null hypothesis in every case. In fact, the statistical power decreases as the number of restrictions increases, leading to an unacceptable level of Type II error. JTTW overcome these limitations by introducing the Min-t test methodology ${ }^{3}$ and employing the stationary bootstrap procedure proposed by Politis and Romano (1994), which allows for time dependence and stationary residuals, to estimate the $p$-values. The assumption that the incremental trading profits innovations are normal and uncorrelated seems very restrictive as Affleck-Graves and McDonald (1989) and Lo and MacKinlay (1988) suggest. For this reason, JTTW test the case in which the innovations $z_{i}$ follow a stationary weakly dependent process. Thus, both HJTW and JTTW impose a MA(1) process for $z_{i}$ to test if it could improve the statistical efficiency of the remaining parameter estimates and avoid inappropriate standard errors. Nevertheless, JTTW show that allowing for this serial correlation does not change their conclusions significantly.

3 As the four restrictions $R_{i}$ must be simultaneously satisfied to reject the null hypothesis of no statistical arbitrage, the minimum of their associated t-statistics serves as a rejection criterion. Thus, Min-t test considers separately the t-statistics associated with the four restrictions $R_{1}, R_{2}, R_{3}$ and $R_{4}$ and finds the minimum. 


\section{A new test of statistical arbitrage}

This paper presents an enhancement with respect to JTTW methodology. The reason is that assuming stationarity seems restrictive when modeling financial time series. Just as it is also restrictive to treat the errors in any empirical econometric work as homoskedastic. We allow incremental trading profits series to be nonstationary and innovations $z_{i}$ to be nonnormal, autocorrelated, heteroskedastic and possibly nonstationary. In this more general situation, the use of the stationary bootstrap is not advisable for estimating the for the Min-t statistics. ${ }^{4}$ Thus, we employ a new test from the use of the subsampling method introduced in Politis, Romano, and Wolf (1995) and (1997) and extended in Politis, Romano, and Wolf (1999a, 1999b) and (2001).5 We construct an asymptotically valid test for UM and CM models based on test statistics which are formed from the quasi-maximum likelihood (QML) estimators in equation (4). It should be highlighted that the statistical arbitrage test is employed to find persistent mispricings. These mispricings can also be understood as statistical arbitrage opportunities under the absence of market frictions.

Let $\left(x_{1}, \ldots, x_{n}\right)$ be a sample of $n$ observations that are distributed in a sample space $S$. The common unknown distribution generating the data is denoted by $P$, the null hypothesis $H_{0}$ asserts $P \in P_{0}$, and the alternative hypothesis $H_{1}$ is $P \in P_{1}$, where $P_{j} \subset P$ for $j=0,1$, and $P_{0} \cup P_{1}=P$. Our purpose is to create an asymptotically valid test based on a given test statistic for the case in which the null hypothesis translates into a null hypothesis about a real-valued parameter $\xi_{i}(P)$. The test statistic is defined as:

$$
T_{i, n}=\tau_{n} t_{i, n}\left(X_{1, \cdots,} X_{n}\right)=\tau_{n}\left(\hat{\xi}_{i, n}\left(X_{1, \cdots}, X_{n}\right)-\xi_{i, 0}\right) \text { for } i=(1,2,3,4)
$$

4 Stationary bootstrap is generally applicable for stationary weakly dependent time series. Subsampling allows for a more general structure in the innovations. Thus, in Politis, Romano, and Wolf (1997), it is shown that in the presence of heteroskedasticity in residuals, subsampling gives better results for the right choice than moving blocks bootstrap methods. This choice is not affected materially by the degree of dependence in the residuals. Moreover, one should obtain better information about the sampling distribution of the statistic using the subsampling methodology. The reason is that, while the subsample statistics are always generated from the true model, bootstrap data come from an approximation to the true model. Another advantage of subsampling is that it has been shown to be valid under very weak assumptions.

5 One could expect that both the increment in the discounted cumulative trading profits and the innovations should be stationary. Nevertheless, our sub-samples only span two years each and a unit root test in this case usually has low power [see Shiller and Perron (1985)]. It should be noted however, that subsampling methodology allows for a more general process both in profits and innovations and even for nonstationarity in some cases. 
where $\tau_{n}$ is a normalizing constant and, as in regular cases, we set $\tau_{n}=n^{\frac{1}{2}}$, $\hat{\xi}_{i, n}=\hat{\xi}_{i, n}\left(X_{1}, \cdots, X_{n}\right)$ is the estimator of $\xi_{i, n}\left(P_{i}\right) \in \mathbb{R}$, which is the parameter of interest, $P_{i}$ denotes the underlying probability distribution of the $i t h$ and $\xi_{i, 0}$ is the value of $\xi_{i, n}$ under the null hypothesis. Each of the four statistics are defined from the restrictions $R_{i}^{c}$ in Subsection 2.3 which lead to four contrasts of hypothesis based on real-valued parameters such that:

$$
\left\{\begin{array}{ll}
H_{0}: & \xi_{i}(P) \leqslant \xi_{i, 0} \\
H_{1}: & \xi_{i}(P)>\xi_{i, 0}
\end{array} \text { for } \quad i=(1,2,3,4)\right.
$$

where $\xi_{i, 0}$ is equal to zero in our analysis. The test is applied to the union of restrictions $R_{i}^{c}$ and so, the non rejection of one of the four null hypotheses automatically confirms the absence of statistical arbitrage.

The distribution of the ith statistic $T_{i, n}$ under $P_{i}$ can be denoted by:

$$
G_{i, n}\left(x, P_{i}\right)=\operatorname{Prob}_{P_{i}}\left\{T_{i, n}\left(X_{1, \cdots,} X_{n}\right) \leq x\right\}
$$

where $G_{i, n}\left(, P_{i}\right)$ converges in distribution at least for $P_{i} \in P_{i, 0}$, where $P_{i, 0}$ denotes the probability distribution under $H_{0}$.

Because $P_{i}$ is unknown, $G_{i, n}\left(, P_{i}\right)$ is unknown and the sampling distribution of $T_{i, n}$ is approximated by:

$$
\hat{G}_{i, n, b}(x)=\frac{1}{n-b+1} \sum^{n-b+1} 1\left\{\tau_{b} t_{i, n, b, t}\left(X_{1}, \cdots, X_{n}\right) \leq x\right\}
$$

where 11 is an indicator function, $\tau_{b}=b^{\frac{1}{2}}$ such that $\frac{\tau_{b}}{\tau_{n}} \rightarrow 0$ as $\mathrm{n} \rightarrow \infty, n-b+1$ indicates the number of subsets of $\left(X_{1}, \ldots, X_{n}\right)$ and $t_{i, n, b, t}\left(X_{1}, \ldots, X_{n}\right)$ is the statistic evaluated at the block of data $\left(X_{t, \cdots}, X_{t+b-1}\right)$ which is defined as:

$$
t_{i, n, b, t}\left(X_{1, \cdots,}, X_{n}\right)=\hat{\xi}_{i, n, b, t}\left(X_{t, \cdots, X_{t+b-1}}\right)-\hat{\xi}_{i, n, t}
$$

where $\hat{\xi}_{i, n, b, t}$ is the estimator of $\xi_{i, n}\left(P_{i}\right) \in \mathbb{R}$ based on the subsample $\left(X_{t, \cdots,} X_{t+b-1}\right)$ and $\hat{\xi}_{i, n, t}$ is the estimator of $\xi_{i, n}$ for the whole sample.

The only assumptions that will be needed to consistently estimate the cumulative distribution function $G_{i, n}\left(x, P_{i}\right)$ are the following:

(i) The estimator, properly normalized, has a limiting distribution.

(ii) For large $n$, the distribution function of the normalized estimator based on the subsamples will be, on average, close to the distribution function of the normalized estimator based on the entire sample.

Using this estimated sampling distribution, we can compute the critical value for the test at least under the null hypothesis. It is obtained as the $1-\alpha$ quantile of $\hat{G}_{i, n, b}(x)$ :

$$
g_{i, n, b}(1-\alpha)=\inf \left\{x: \hat{G}_{i, n, b}(x) \geqslant 1-\alpha\right\}
$$


Our purpose is to test if $T_{n}$ is rejected at a level of significance $\alpha$ depending on whether the statistic exceeds the exact $1-\alpha$ quantile of the true sampling distribution $G_{n}(x, P)$, that is $g_{n}(1-\alpha, P)$. Of course, $P$ is unknown and so is $g_{n}(1-\alpha, P)$. However and according to Politis, Romano, and Wolf (1999a), the asymptotic power of the subsampling test against a sequence of contiguous alternatives $\left\{P^{n}\right\}$ to $P$ with $P$ in $P_{0}$ is the same as the asymptotic power of this fictitious test against the same sequence of alternatives. For this reason and given that there is no loss in efficiency in terms of power, we test the statistic $T_{n}$ against the $1-\alpha$ quantile under $P_{0}, g\left(1-\alpha, P_{0}\right)$.

The steps in which subpsampling technique is applied in this study are as follows:

1. Once the parameters have been estimated by QML, we calculate the test statistic for the whole sample:

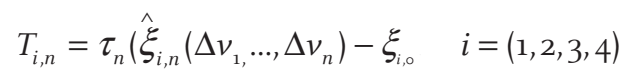

and the estimated residuals $\hat{z}_{i}: 6$

$$
\hat{z}_{i}=\frac{\Delta v_{i}-\hat{\mu} i^{\hat{\theta}}}{\hat{\sigma} i^{\hat{\lambda}}} \quad i=1, \ldots n
$$

2. We create subsamples of consecutive blocks of data with length $b$ such that the first subsample of residuals is defined by $\left(\hat{z}_{1}, \ldots, \hat{z}_{b}\right)$, and so on.

3. We generate $n-b+1$ successive subsamples of trading profits $\left(\Delta v_{i}^{*}, \ldots, \Delta v_{i+b-1}^{*}\right)$ from the corresponding residuals $\left(z_{i}, \ldots, z_{i+b}\right)$ for $i=1, \ldots, n-b$. The trading profits are calculated with the parameters under the null hypothesis such that their values bind the restrictions. Thus, the parameter values are $(\mu, \sigma, \theta, \lambda)=\left(-10^{-6}, \hat{\sigma},-1,-0.5\right)$ for the UM model and $(\mu, \sigma, \lambda)=(0, \hat{\sigma}, 0)$ for the CM model: ${ }^{7}$

$$
\Delta v_{i}^{*}=\mu i^{\theta}+\hat{\sigma} i^{\lambda} \hat{z}_{i}
$$

4. We estimate $n-b+1$ times by QML the parameters for the successive blocks and for every block we calculate the statistic $t_{i, n, b, t}$ such that we have $n-b+1$ statistics.

5. Finally we approximate the sampling distribution of $T_{i, n}$ by means of the estimated sampling distribution $\hat{G}_{i, n, b}(x)$ as in equation (9) and compute the critical values $g_{i}\left(1-\alpha, P_{0}\right)$ as in equation (11) under the null hypothesis. We reject the null hypothesis at a degree of significance of $\alpha$ if and only if $T_{i, n}$ exceeds the corresponding critical value $g_{i}\left(1-\alpha, P_{0}\right)$.

6 We find that the residuals follow ARMA processes and, in some cases, they even present heteroskedasticity. These facts suggest that it is unduly restrictive to impose a $M A(1)$ process for $z_{i}$.

7 For the UM model, five restrictions should be simultaneously satisfied to prove the existence of statistical arbitrage. However, these five restrictions involve three parameters and not all the restrictions are necessarily binding. As HJTW suggest, a model within the null family and on the boundary of all the inequality restrictions is not available. We employed other values of $\mu$ such as -0.0001 or $-10^{-8}$ to have $\theta$ in the equation, but results are similar in the three cases. The values of parameters $\theta$ and $\lambda$ bind the third restriction and we employ them due to their good properties in JTW. Parameter $\hat{\sigma}$ does not appear in the restrictions and we use the value of the QML estimator for $\sigma$ in the whole sample. 
There is not a universal prescription for the choice of the optimal block size. Moreover, Politis, Romano, and Wolf (1999a) show that subsampling works quite well even with a data-driven choice of block size. Block sizes should not be too large or small but the effect of different choices of $b$ diminishes as the sample size increases. ${ }^{8}$

In the correct range of $b$, the confidence intervals should be stable when considered as a function of the block size. For this reason, we use the method defined by Politis, Romano, and Wolf (1999a) as the Minimum Volatility Method to select the optimum $b$ :

1. Compute a subsampling quantile $g_{n, b}(1-\alpha)$ for $b=b_{\text {small }}=n^{\frac{4}{10}}$ to $b=b_{\text {big }}=n^{\frac{9}{10}}$.

2. For each $b$ compute a volatility index as the standard deviation of the quantiles in a neighborhood of $b, V I\left(g_{n, b-k}(1-\alpha), g_{n, b}(1-\alpha), g_{n, b+k}(1-\alpha)\right)$ with $k=2$.

3. Pick the value $b^{*}$ corresponding to the smallest volatility index and use $g_{n, b^{*}}(1-\alpha)$ as the critical value of the test.

After estimating the optimal block size, we confirm, as expected, that there is not a common optimum block size for every sample. In most cases, the optimum block size is such that the ratio block size/sample size is between 0.15 and $0.5 .{ }^{9}$ Larger blocks are needed to capture stronger dependence in the innovations.

We now compare our new test (MPR test henceforth) against the JTTW test looking at their Type I errors. Given that the null hypothesis is no statistical arbitrage opportunities it seems advisable to choose the test with lower false positive record (i.e. the most conservative). The absence/existence of statistical arbitrage is based on three hypotheses, each of them associated to different requirements, or equivalently, on four restrictions $R_{i}^{c}$ (see Subsection 2.3). We study both tests using simulations of the series of the increment in the discounted cumulative trading profits. The simulation results are in Table 1 . The profits are simulated by setting parameters $\mu, \theta$ and $\lambda$ such that they hold one given restriction $R_{i}^{c}$, which corresponds to the complementary of one of the three hypotheses in Subsection 2.2, and do not hold the remaining ones. The parameters employed to simulate the profits are close to the limits of the existence/absence of statistical arbitrage to discriminate between both tests in the most detailed way as possible. ${ }^{10}$ This allows us to have a further perspective of the individual restrictions. We perform one hundred different simulations with a sample size of 400 observations. This length is close to the average number of observations or investment days in the different cases analyzed in this paper. Moreover, as a test of conver-

8 For $b$ too close to $n$ all subsample statistics $\hat{\xi}_{i, n, b, t}$ will be almost equal to $\hat{\xi}_{i, n^{\prime}}$ resulting in the subsampling distribution being too tight and in undercoverage of subsampling confidence intervals. For $b$ too small, the intervals can undercover or overcover depending on the state of nature.

9 We require that the selected block size, $b$, can also be obtained from the expression $b=n^{x}$ with $x<1$. It guarantees that the required assumption which states that $b \rightarrow \infty$ as $n \rightarrow \infty$ and $\frac{b}{n} \rightarrow 0$ as $n \rightarrow \infty$ is fulfilled.

10 The restriction that holds is related with each of the three requirements needed for the existence/absence of statistical arbitrage. We first compare both tests using simulations where the first restriction, $R_{1}^{c}$ holds and employing as parameters: $\mu=-0.001, \sigma=1, \theta=0.5$ and $\lambda=-0.5$. The second comparison is based on the ability of the tests to detect the cases in which $R_{2}^{c}$ holds and we employ as parameters: $\mu=-1, \sigma=1, \theta=0.1$ and $\lambda=-1.05$. Finally, we evaluate the case in which both $R_{3}^{c}$ and $R_{4}^{c}$ hold according to the following parameters: $\mu=1, \sigma=1, \theta=1.05$ and $\lambda=-0.45$. Note that the last case involves two restrictions; the reason is that both of them are associated with the requirement which states that the probability of loss converges to zero. 
gence, we simulate a series of profits with a sample length equal to 5,000, and find that the estimated coefficients are exactly the same to the ones employed to do the simulation. As we find that the residuals are neither normal nor follow a $M A(1)$ process, which is the process imposed in JTTW methodology, we compare both test after generating randomly the residuals according to three different processes: i.i.d. normal residuals; the residuals follow an $A R M A(1,1)$ process with the $A R$ and $M A$ coefficients equal to 0.9 and 0.75 , respectively; or the residuals follow an $A R M A(1,1)$ process such that the coefficients of the $A R$ and $M A$ parts are 0.5 and 0.75 , respectively.

We find that both tests are equally effective when either restriction $R_{1}^{c}$, which states that the expected cumulative discounted profits are negative, or restrictions $R_{3}^{c}$ and $R_{4}^{c}$, which state that the probability of loss does not converge to zero, hold. When restriction $R_{2}^{c}$, which states that the variance of the incremental trading profits does not converge to zero, hold, we find that our test cannot reject the absence of statistical arbitrage at any standard confidence level. However, JTTW's test signals the existence of statistical arbitrage at confidence levels between $1 \%$ and $5 \%$, depending on the residuals process, when in fact there is no arbitrage opportunity. These results suggest that some arbitrage opportunities detected by JTTW's test do not satisfy condition (iv) in page 6 (investors only care about downside risk) whereas that condition is fully satisfied in all cases by our test. This discrepancy between both tests may be due to the different information about the sampling distribution and the dependence structure of the statistic that is employed by the subsampling and the bootstrap methodologies. There is a salient economic implication of this fact: traders relying in JTTW's test will sometimes try to profit from apparent arbitrage opportunities but will incur unknowingly in substantial downside risk. Traders using our test will not take into account those apparent (but risky) arbitrage opportunities.

MPR and JTTW tests' Type I Errors Analysis

TABLE 1

\begin{tabular}{|c|c|c|c|c|c|c|}
\hline & \multicolumn{2}{|c|}{$\begin{array}{l}\text { i.i.d. normal } \\
\text { residuals }\end{array}$} & \multicolumn{2}{|c|}{$\begin{array}{r}\operatorname{ARMA}(1,1)= \\
(0.5,0.75)\end{array}$} & \multicolumn{2}{|c|}{$\begin{array}{r}\operatorname{ARMA}(1,1)= \\
(0.9,0.75)\end{array}$} \\
\hline & MPR & JTTW & MPR & JTTW & MPR & JTTW \\
\hline $\begin{array}{l}\mathrm{H} 1: \mu>0 \\
\text { No } H 1:(\mu=-0.001 ; \sigma=1 ; \theta=0.5 ; \lambda=-0.5)\end{array}$ & 0,79 & 0,64 & 0,82 & 0,77 & 0,80 & 0,89 \\
\hline $\begin{array}{l}H 2: \lambda<0 \cup \theta>\lambda \\
\text { No } H 2:(\mu=1 ; \sigma=1 ; \theta=0.1 ; \lambda=0.05)\end{array}$ & 0,44 & 0,01 & 0,48 & 0,02 & 0,57 & 0,04 \\
\hline $\begin{array}{l}\text { H3: } \theta>\max \{\lambda-1 / 2,-1\} \\
\text { No } H 3:(\mu=1 ; \sigma=1 ; \theta=-1.05 ; \lambda=-0.45)\end{array}$ & 0,60 & 0,51 & 0,64 & 0,47 & 0,72 & 0,84 \\
\hline
\end{tabular}

This table reports the Type I errors obtained with our test (MPR) and the JTTW test, that is, it shows the confidence level at which the tests signal the existence of statistical arbitrage when there is no statistical arbitrage opportunity. The best test is the one with the lowest "false positive" record (i.e. the most conservative). The existence of statistical arbitrage is based on three hypotheses, each of them associated to different requirements, or equivalently, on four restrictions Rci (see Subsection 2.3). We study both tests using simulations of the series of the increments in the discounted cumulative trading profits. These profits are simulated by setting parameters $\mu$, $\theta$, and $\lambda$, and $\sigma$ such that they hold one given restriction Rci, which corresponds to the complementary of one of the three hypotheses in Subsection 2.2, and do not hold the remaining ones. The parameters employed to simulate the profits are close to the limits of the existence/absence of statistical arbitrage to discriminate between both tests. We first compare both tests using simulations where the first restriction, Rc1, holds and employing as parameters: $\mu=-0.001 ; \sigma=1 ; \theta=0.5 ; \lambda=-0.5$. The second comparison is based on the ability of the tests to detect the cases in which Rc2 holds and we employ as parameters: $\mu=1 ; \sigma=1 ; \theta=0.1 ; \lambda=0.05$. Finally, we evaluate the case in which both Rc3 and Rc4 hold according to the following parameters: $\mu=1 ; \sigma=1 ; \theta=-1.05 ; \lambda=-0.45$. We perform one hundred different simulations with a sample size of 400 observations. We compare both test after generating randomly the residuals according to three different processes: i.i.d. normal residuals; the residuals follow an ARMA $(1,1)$ process with the AR and MA coefficients equal to 0.5 and 0.75 , respectively; or the residuals follow an ARMA $(1,1)$ process with AR and MA parameters set to 0.9 and 0.75 , respectively. 



\section{Empirical application}

\subsection{Cash-and-carry arbitrage strategy}

\subsubsection{Credit default swaps}

A CDS is as a traded insurance contract which provides protection against credit risk until the occurrence of a credit event or the maturity date of the contract, whichever is first, in exchange for periodic premium payments (the CDS premium or CDS spread) and/or an upfront payment. We analyze the case in which the CDSs trade on a full running format (i.e. no upfront). It means that the CDS contract that we employ is unfunded and so, investors do not make an upfront payment (ignoring dealer margins and transaction costs). Thus, the traded CDS premium is an at-market annuity premium rate $\bar{s}$ such that the market value of the CDS is zero at origination. In the event of default, CDSs are settled in one of two ways: by physical settlement or by cash settlement.

The British Bankers' Association estimates that CDSs accounted for $33 \%$ of the market share of credit derivatives in 2006. According to the ISDA statistics, the CDS market exploded over the past decade from a notional amount outstanding of $\$ 8.42$ trillion at the end of 2004 to more than $\$ 45$ trillion in mid-2007 and more than $\$ 62$ trillion at the end of 2007. However, the notional amount outstanding decreased to $\$ 38.6$ trillion at the end of 2008. Most CDSs are quoted for a benchmark time-tomaturity of five years but since CDSs are traded Over the Counter (OTC) any maturity is possible. The spread is quoted in annual terms but standard premium payments are settled in quarterly terms with an actual/36o day count convention.

\subsubsection{Asset swap packages}

An ASP contains a defaultable coupon bond with coupon $\bar{c}$ and an interest rate swap (IRS) that swaps the bond's coupon into Euribor plus the asset swap spread rate $s^{A}$. The spread is chosen such that the value of the whole package is the par value of the defaultable bond. Thus, an upfront payment must be added to the bond's price at the investment period to ensure that the value of the whole package is the bond face value. The upfront payment represents the net present value of the swap. The asset swap's fixed leg $(\bar{c})$ represents the buyer's periodic fixed rate payments, while its floating leg $\left(\right.$ Euribor $+s^{A}$ ) represents the seller's potential payment. ${ }^{11}$ According to

11 According to the California Debt and Investment Advisory Commission (CDIAC), floating-rate payment intervals in a IRS need not coincide with fixed-rate payment intervals, although they often do. Thus, the ASP investors could make the fixed rate payments dates to coincide with the defaultable bond's coupon payments dates while the floating payments, Euribor plus asset swap spread, could be made quarterly. 
Schonbucher (2003), it is even easier to trade an ASP than the underlying defaultable bond alone.

\subsubsection{Cash-and-carry strategy}

A combined long position in a CDS (buy protection) and an ASP is hedged against bond's default risk and should therefore trade close to the price of an equivalent default free bond. This is the intuition behind the cash-and-carry arbitrage pricing of CDSs. From cash-and-carry strategies, we construct two equivalent portfolios which should produce the same payments at the same time. Then, we analyze the existence of possible mispricings that could derive in arbitrage opportunities.

\section{Portfolio I:}

- $\quad$ Long position in a CDS with an annual full running premium equals to $\bar{s}$ which is paid quarterly.

Portfolio II:

- $\quad$ Long position in an ASP whose cost is equal to the bond's par value. The investor pays to the counterparty the bond's coupon at the coupon dates in exchange for receiving every quarter the 3-month Euribor rate $\left(E_{3 m}\right)$ plus the asset swap spread $\left(s^{A}\right)$.The quarterly payment dates coincide with the CDS premium payment dates.

- $\quad$ Loan (principal equals to the bond's face value) at 3-month Euribor. Interest payment dates coincide with both CDS premium and ASP floating leg payment dates.

Portfolio II is equivalent to a synthetic short position in a CDS and so, there should be an equivalence relation between CDS and asset swap spreads. Otherwise and ignoring the effects of potential market frictions, arbitrage opportunities could appear. We first assume that the investor can borrow money at Euribor flat for the entire duration of the trade and after, we relax this assumption and estimate the critical level of average funding costs which delimits the existence/absence of statistical arbitrage.

At origination the cost of both portfolios is zero, and so the net payoff is also zero. The investor pays the CDS premium $\left(\bar{s}_{t}\right)$, receives the floating leg payment of the ASP $\left(E_{3 m, t}+s_{t}^{A}\right)$ and pays the interest associated with the loan $\left(E_{3 m, t}\right)$. The net payment is equal to the difference between ASP and CDS spreads $\left(s_{t}^{A}-\vec{s}_{t}\right)$ converted into quarterly terms using an actual $/ 360$ day count convention. The previous difference is known as the basis. To be consistent with the market's conventional definition of the CDS-ASP basis we define it as the difference between the CDS and bond spreads. For this reason, the strategy's net payment is equivalent to the opposite of the CDSASP basis and so, when these payments are positive, this implies a negative basis. This payment is repeated every quarter up to maturity or default, whichever comes first. The existence of funding costs $(F)$ would transform the net payment into $\left(s_{t}^{A}-\bar{s}_{t}-F\right)$. 
At the coupon payment dates, the investor receives the coupon $(\bar{c})$ from the underlying bond and delivers it to the asset swap counterparty as the fixed leg payment. Thus, net payoff at the coupon payment date is zero. At the bond's maturity, the investor receives the bond's face value plus the final coupon payment. The coupon is delivered to the ASP counterparty as the IRS fixed leg payment while the bond's face value is employed to refund the loan's principal. From the IRS floating leg, the investor receives 3-month Euribor rate plus the ASP spread. The former is employed to pay the loan's interest. Finally, the investor must pay the CDS spread, which is the price for credit risk protection. Then, the net payoff is also equal to the opposite of the bond-CDS basis. ${ }^{12}$

We analyze the existence of profitable arbitrage opportunities in a realistic setting and therefore we consider the potential restrictions that a given investor could face in the market. For this reason, we employ CDSs with a notional equal to $€_{500,000}$ and assume that the strategy stops if the total investment in a given bond exceeds $25 \%$ of the bond's issued amount. ${ }^{13}$ As an additional restriction, the strategy stops if the total expected future losses exceed $€_{25}$,000. Finally, the strategy also stops if there are two downgrades which place the firm in BBB- rating category. The strategy's payments are equal to the opposite of the CDS-ASP basis unless there is default to avoid any bias due to potential future defaults and for this reason we restrict our sample to investment grade firms. Once the strategy's investments stop, future payments are fully known because both CDS and asset swap spreads are set at the investment date. Moreover, we assume that the market segmentation does not affect the arbitrageur, who has no restriction on participating in the CDSs market. The cumulative trading profits obtained at every period are discounted up to the initial date. Thus, we obtain the increment in the discounted cumulative trading profits at a given date $t, \Delta v(t)$, as the difference between the discounted cumulative trading profits at $t$ and at $t-1 .{ }^{14}$

12 In case of default, at a given date $\tau$, the investor recovers a portion of the bond face value $\mathrm{R}(\tau)$, and through the protection bought in the CDS, the investor receives the difference between the bond face value and the recovery rate $(F V-R(\tau))$. The investor employs the amount equal to the bond face value $F V$ to refund the loan. The net payment at default is then composed by: (i) the value of the IRS included in the ASP which remains alive after default and must be serviced or unwound at market value; (ii) the payment of the CDS accrued premium from the last payment date to the credit event; (iii) the payment of the loan accrued interest from the last payment date to the credit event; (iv) the value of the cheapestto-deliver (CTD) option which appears because in the event of a default, not only the underlying bond but a given number of bonds, some of them cheaper than the underlying, can be delivered. The strategy net payments are equal to the basis defined as $s_{t}^{A}-\bar{s}_{t}$ except in case of default. In practice the asset swap spread plus Libor tends to be greater than the bond coupon and in the event of a default, the investor will usually continue to receive a small annual income from the trade. Other potential assumption, for simplicity, could be to assume that the asset swap is a perfect asset swap and the future cash flows disappear upon default.

13 The CDS typical notional amount is €10-20 million for investment grade credits and $€ 1-5$ million for high yield credits and the standard bond's face value is $€ 1,000$. Successive repetitions of this strategy might imply high demand of a given bond that could exceed the issued amount. For this reason, we employ CDSs with a notional equal to $€ 500,000$. This notional is high enough to deal with fixed costs and is of adequate size to guarantee that a substantial number of investments can be made.

14 It should be mentioned that a simpler methodology to test for arbitrage would implement a buyand-hold strategy that ends after five years. However and given that a standard arbitrage opportunity is a special case of statistical arbitrage our procedure will detect any simpler arbitrage opportunities. 
This strategy is known as trading the basis. The profitabilty of the basis trading lies on potential mispricings which lead to deviations in the equivalence relation that should exist between the CDS and the ASP/bond spreads. Thus, basis trades exploit the different pricing of ASP/bond and CDS on the same underlying company. According to Elizalde, Doctor, and Saltuk (2009), the basis trades based on long positions in ASPs/bonds and CDSs (to benefit from a negative basis) have been a popular investment strategy during the last years. In fact, they represent one of the closest trading techniques in the credit market to an arbitrage free trade given that the investor is not exposed to risk but still receives the difference between the ASP and CDS spreads.

We employ a long-run investment strategy to detect the existence of possible persistent anomalies instead of punctual deviations between credit spreads. For this reason, the same self-financing strategy based on the same individual bond should be repeated across time, maintaining all the terms and conditions. Thus, the payment on a given date is added to the cumulative trading profits from the first investment date to the day before, which were invested or borrowed at the risk-free rate a day ago.

In the previous analysis, we do not address the existence of persistent positive bases (the CDS spread is persistently higher than the ASP spread) given that it is not usually viable for the arbitrageurs to exploit them due to the restrictions in the bond/ ASP short-positions. We study the existence of persistent negative bases and then analyze if these deviations from the theoretical equivalence relation between the CDS and the ASP spreads may lead to profitable statistical arbitrage opportunities.

\subsection{Data}

Our database contains daily data on Eurobonds and ASPs denominated in Euros and issued by nonfinancial companies that are collected from Reuters and Datastream and on CDSs also denominated in Euros, whose underlying firms are the same nonfinancial companies, that are obtained from four different databases: GFI, Reuters, CMA, and J. P. Morgan.

We employ four different CDSs databases to have more robust results and to minimize the possibility that measurement errors could affect our results. This variety of sources also serves as a check of the reliability of our data. The first source we employ is GFI which is a major inter-dealer broker (IDB) specializing in the trading of credit derivatives. GFI data contain single name CDSs market prices for 1, 2, 3, 4, and 5 years maturities. These prices correspond to actual trades, or firm bids and offers where capital is actually committed and so, they are not consensus or indications. ${ }^{15}$ Thus, these prices are an accurate indication of where the CDS markets traded and closed for a given day. For some companies and for maturities of two and four years, the data availability is scarce and in these cases, whenever there exist

15 Consensus and indicative data are trusted less now that the markets are so volatile. There exist differences of up to $100 \%$ between consensus prices from leading providers compared to actual trades on GFI systems. The reason is that consensus is inherently slow and the prices originate from back office staff who can be swayed by the positions they hold and they do not have a front office view. 
data on CDSs actual market prices for the maturity of five years, we employ midprice quotes from a credit curve also reported by GFI. ${ }^{16}$ We take advantage of the range of CDSs maturities to fit a CDS curve using a Piecewise Cubic Hermite Interpolating Polynomial (PCHIP) algorithm that permits us to match ASP and CDS maturities. This method is also used in Levin, Perli, and Zakrajšek (2005). GFI data have also been used by Hull, Predescu, and White (2004), Predescu (2006), Saita (2006), Nashikkar and Subrahmanyam (2007), Fulop and Lescourret (2007), or Nashikkar, Subrahmanyam, and Mahanti (2009) among others.

The second source is Reuters. Reuters takes CDS quotes each day from several contributors around the world and offers end of day data for single names CDSs. Before computing a daily composite spread, it applies a rigorous screening procedure to eliminate outliers or doubtful data. According to Longstaff, Mithal, and Neis (2005), as the data include quotations from a variety of credit derivatives dealers, these quotations should be representative of the entire credit derivatives market. Jankowitsch, Pullirsch, and Veža (2008), among others, employ CDSs data from Reuters.

The third source is Credit Market Analysis (CMA) DataVision(TM). CMA DataVision is consensus data sourced from 30 buy-side firms, including major global Investment Banks, Hedge Funds, and Asset Managers which offers quoted CDS prices (bid, ask and mid). Among the papers that employ CMA data we mention Nashikkar and Subrahmanyam (2007) and Nashikkar, Subrahmanyam, and Mahanti (2009).

Our fourth database, employed also in Aunon-Nerin, Cossin, Hricko, and Huang (2002), Blanco, Brennan, and Marsh (2005), and Chen, Cheng, and Liu (2008) among others, contains mid-market data provided by J. P. Morgan which is one of the leading players and most active traders in the CDS market.

Given the four different data sources on CDSs spreads, we cross-check the data using all the sources to confirm the validity of any CDS price. Due to liquidity restrictions and to require that investments take place whenever there is trading activity, these investments are restricted to dates when we observe 5-year CDS actual trades or firm bids and offers where capital is actually committed according to GFI data. ${ }^{17}$ The results that we report in the paper are the ones obtained with GFI data.

For each bond there is information on both bid and ask prices, the swap spread, the asset swap spread, the sector of the entity and its geographical location, the currency, the seniority, the rating history (Fitch, S\&P, and Moody's ratings), the issuance

16 The GFI FENICS ${ }^{\circledR}$ Credit curves are generated each hour for over 1900 reference entities. Data points in each curve can be actual trades or mid prices calculated from the bid/offer quotes, and in their absence GFI will calculate a running point level using the Hull and White methodology to ensure a credit curve always exists for each reference entity. This curve is a good approximation for CDSs at any maturity. The median of the absolute difference in basis points between five years CDS premiums as defined from credit curve and the actual quotes or transaction prices for the period between April 2001 and May 2002, is equal to 1.16, 2.01 and $3.82 \mathrm{bps}$ for AAA/AA, A and BBB ratings for a total of 2,659, 9,585 and 8,170 companies respectively. Moreover, market CDS spread could be different from what we are assuming to be the true CDS spread by as much as 3.725 bps. on average.

17 Even when CDS quotes, from any of the data sources, are available at a given date, we do not employ them unless we observe 5-year CDS data from GFI. Thus, these dates do not indicate missing observations in a given source of data, but lack of trading activity. 
date and the amount issued, the coupon and coupon dates, and the maturity. We use bonds whose maturity at the investment dates is lower than five years. Several bonds issued by the same company are used whenever they satisfy all the required criteria. The reason is that although CDS spreads quotes are referred to the issuer and not to an individual bond, asset swap spreads are quoted for individual bonds. Due to liquidity considerations, bonds with time to maturity equal to or less than twelve months in the date corresponding to their last observation are excluded. Moreover, our sample contains fixed-rate senior unsecured Euro denominated bonds whose issued quantity exceeds 300 millions of Euros. Other requirements imposed on bonds to be included in the sample are: i) straight bonds, ii) neither callable nor convertible, iii) with rating history available, iv) with constant coupons and with a fixed frequency, v) without a sinking fund, vi) without options, vii) without an odd frequency of coupon payments, viii) no government bonds, and ix) no inflation-indexed bonds. We also cross-check the data on bonds with the equivalent data obtained from Datastream.

The data span from November 1st, 2005 to June 29th, 2009. However, we split the data into two subperiods to take into account the possible effects of the ongoing financial crisis. The first subperiod covers the period from November 1st, 2005 to August 8th, 2007 while the second one spans from August 9th, 2007 to June 29th, 2009. Our sample size is comparable to others in the literature on CDS and bond spreads, both in terms of sample size and number of companies. ${ }^{18}$ The final sample consists of 49 nonfinancial companies and 64 bonds. In the first subsample we employ 55 bonds and 41 companies while in the second one we use 46 bonds and 36 companies. ${ }^{19}$ Table 2 presents information about ASPs, bonds, and CDSs in the two different periods under study. As shown in Panel B of Table 2, there is a great deal of variation in the amount issued and, in the first period, in the sample size. This panel shows that bonds traded, on average, above par in the first period and below par in the second one. Panel C presents descriptive statistics for the opposite of the CDS-ASP basis, that is, for the difference between the ASP and the CDS spreads, for the first and second subperiods, respectively. We observe that, before the crisis, the average difference between the ASP and the CDS spreads is negative for 17 of the 55 issues (positive basis) while this difference is negative for 20 of the 46 issues during the crisis. On average, the basis is lower and much more volatile in the second period which suggests that arbitrage strategies become riskier during the crisis.

18 Longstaff, Mithal, and Neis (2005) include 68 firms from March 2001 to October 2002, Blanco, Brennan, and Marsh (2005) use 33 American and European companies from January 2001 to June 2002, Zhu (2006) use 24 investment grade companies from January 1999 to December 2002, and Forte and Peña (2009) employ data for 20 companies from September 2001 to June 2003.

19 Our initial sample was formed by 301 corporate bond issuers. We found a total of 135 Euro denominated bonds that mature before June 2012 but only 85 of them include reliable information on the CDS spreads and the asset swap spreads. Of these, 3 bonds have been discarded because the issued amount does not exceed 300 million Euros, another 4 bonds were discarded because they were not investment grade bonds during the whole sample period. The time to maturity was lower than twelve months by August 2007 for 4 bonds that were discarded, another 3 bonds were discarded because their asset swap spreads were persistently negative and, finally, 7 bonds were discarded because prices were too far from par. Thus, although we consider all the bonds issued by nonfinancial European companies to be employed in our study, the final number of bonds is 64 due to the imposed requirements. 
Panel A

\begin{tabular}{|c|c|c|}
\hline Issuer & Rating & Sector \\
\hline Akzo Nobel & $\mathrm{A}-/ \mathrm{BBB}+$ & Chemicals \\
\hline Altadis & $\mathrm{BBB} /-$ & Beverages \& Tobacco \\
\hline Astrazeneca & - / AA- & Pharmaceuticals \& Biotechnology \\
\hline Auchan & $-/ A$ & Retail - Department Stores \\
\hline BASF & $-/ A+$ & Chemicals \\
\hline Bayer & $-/ A-$ & Chemicals \\
\hline Belgacom & $-/ A+$ & Fixed-Line Telecommunication Svs. \\
\hline BMW & $A+/ A$ & Automobile \\
\hline Bouygues & $\mathrm{BBB}+/ \mathrm{BBB}+$ & Construction \\
\hline British AM Tob. & $\mathrm{BBB}+/ \mathrm{BBB}+$ & Beverages \& Tobacco \\
\hline Carrefour & $\mathrm{A} / \mathrm{A}$ & Food \& Drug Retailers \\
\hline Casino G. P. & BBB- / BBB- & Food \& Drug Retailers \\
\hline Compass Group & $\mathrm{BBB}+/-$ & Support Services \\
\hline Edison & $\mathrm{BBB}+/ \mathrm{BBB}+$ & Public Utilities \\
\hline Enel & A- / A- & Public Utilities \\
\hline Energias de Portugal & A- / A- & Electricity \\
\hline E.ON & $A+/-$ & Utilities \\
\hline France Telecom & A- / A- & Fixed-Line Telecommunication Svs. \\
\hline Iberdrola & $A / A-$ & Petrol and Power \\
\hline Kingfisher & BBB- / BBB- & General Retailers \\
\hline Louis Vuitton & $\mathrm{BBB}+/ \mathrm{BBB}+$ & Other Textiles and Leather Goods \\
\hline Philips & $-/ A-$ & Electronic \& Electrical Equipment \\
\hline PPR & BBB- / BBB- & Retailers - Multi Department \\
\hline Reed Elsevier & A- / - & Media \& Entertainment \\
\hline Renault & $\mathrm{BBB}+/-$ & Automobiles \\
\hline Repsol YPF & $\mathrm{BBB}+/ \mathrm{BBB}+$ & Petrol and Power \\
\hline Reuters & A- / - & Publishing \\
\hline Saint Gobain & $\mathrm{BBB}+/ \mathrm{BBB}+$ & Building and Construction Materials \\
\hline Scania & A- / - & Machinery and Engineering \\
\hline Schneider & $-/ A-$ & Electrical Equipment \\
\hline SES & $\mathrm{BBB} / \mathrm{BBB}$ & Telecommunications \\
\hline Siemens & $\mathrm{AA}-/ \mathrm{A}+$ & Industrial \\
\hline Sodexho & $\mathrm{BBB}+/-$ & Business Support Services \\
\hline Stora Enso & BBB- / - & Forest Product \& Paper \\
\hline Technip & $\mathrm{BBB} / \mathrm{BBB}$ & Oil - Services \\
\hline Telecom Italia & $\mathrm{BBB}+/ \mathrm{BBB}$ & Public Utilities \\
\hline Telefonica & $\mathrm{BBB}+/ \mathrm{A}-$ & Technology and Telecommunications \\
\hline Telekom Austria & $\mathrm{BBB}+/ \mathrm{BBB}+$ & Machinery, Transport and Technology \\
\hline Teliasonera & $-/ A-$ & Telecommunications \\
\hline Tesco & $A / A-$ & Food \& Drug Retailers \\
\hline Thales & A- / A- & Defence \\
\hline Thyssenkrupp & $\mathrm{BBB}+/ \mathrm{BBB}-$ & Industrial \\
\hline Union Fenosa & A- / A- & Petrol and Power \\
\hline Veolia Environ. & $\mathrm{BBB}+/-$ & Water \\
\hline Vinci & $\mathrm{BBB}+/-$ & Other Construction \\
\hline Vivendi & $\mathrm{BBB} /-$ & Subscription Entertainment Networks \\
\hline Vodafone & A- / - & Wireless Telecomunications Svs. \\
\hline Volkswagen & $\mathrm{A}-/ \mathrm{BBB}+$ & Automobile \\
\hline Volvo & $\mathrm{A}-/ \mathrm{BBB}+$ & Machinery \& Engineering \\
\hline
\end{tabular}


Panel B

\begin{tabular}{|c|c|c|c|c|c|c|}
\hline \multirow[b]{2}{*}{ Issuer } & \multirow{2}{*}{$\begin{array}{r}\text { Amount } \\
\text { issued } \\
\text { (millions of } \\
\text { euros) }\end{array}$} & \multirow[b]{2}{*}{$\begin{array}{r}\text { Coupon } \\
(\%)\end{array}$} & \multicolumn{2}{|c|}{ Nov 2005 - Aug 2007} & \multicolumn{2}{|c|}{ Aug 2007 - June 2009} \\
\hline & & & Obs. & $\begin{array}{c}\text { Mean } \\
\text { Price }\end{array}$ & Obs. & $\begin{array}{r}\text { Mean } \\
\text { Price }\end{array}$ \\
\hline Akzo Nobel I & 750 & 4,250 & 220 & 100,03 & 396 & 99,26 \\
\hline Akzo Nobel II & 1.000 & 5,625 & 286 & 103,94 & - & - \\
\hline Altadis & 600 & 4,250 & 330 & 100,32 & - & - \\
\hline Astrazeneca & 750 & 4,625 & - & - & 157 & 100,68 \\
\hline Auchan & 600 & 3,000 & - & - & 169 & 96,69 \\
\hline BASF & 1.400 & 3,375 & - & - & 290 & 97,44 \\
\hline Bayer & 2.000 & 6,000 & - & - & 347 & 104,55 \\
\hline Belgacom & 775 & 4,125 & - & - & 38 & 98,06 \\
\hline BMW & 750 & 3,875 & 295 & 98,63 & 393 & 98,00 \\
\hline Bouygues I & 750 & 4,625 & 197 & 101,40 & 260 & 99,79 \\
\hline Bouyges II & 1.000 & 5,875 & 221 & 104,64 & - & - \\
\hline British AM Tob. I & 1.700 & 4,875 & 338 & 101,86 & - & - \\
\hline British AM Tob. II & 1.000 & 4,375 & 232 & 99,61 & 300 & 98,92 \\
\hline Carrefour I & 1.100 & 4,375 & 221 & 100,22 & 324 & 100,24 \\
\hline Carrefour II & 1.000 & 6,125 & 314 & 107,15 & 324 & 103,45 \\
\hline Casino G. P. I & 400 & 4,750 & 148 & 99,98 & 304 & 98,34 \\
\hline Casino G. P. II & 500 & 5,250 & 195 & 102,18 & 304 & 100,59 \\
\hline Casino G. P. III & 700 & 6,000 & - & - & 304 & 100,74 \\
\hline Compass Group & 300 & 6,000 & 121 & 104,08 & - & - \\
\hline Edison & 700 & 5,125 & 339 & 103,43 & 338 & 101,31 \\
\hline Enel & 750 & 4,125 & 91 & 99,22 & 206 & 100,23 \\
\hline Energias de Portugal I & 1.000 & 6,400 & 184 & 107,40 & 258 & 102,17 \\
\hline Energias de Portugal II & 747 & 5,875 & 162 & 106,80 & 251 & 103,41 \\
\hline E.ON & 4.250 & 5,750 & 200 & 104,44 & - & - \\
\hline France Telecom I & 750 & 4,625 & 119 & 99,77 & 298 & 100,75 \\
\hline France Telecom II & 1.000 & 4,375 & 100 & 98,48 & 298 & 99,49 \\
\hline France Telecom III & 1.000 & 3,000 & 294 & 95,82 & 298 & 97,73 \\
\hline Iberdrola I & 750 & 4,375 & 234 & 98,35 & 291 & 100,06 \\
\hline Iberdrola II & 600 & 4,500 & 195 & 101,36 & - & - \\
\hline Kingfisher & 500 & 4,500 & 270 & 100,11 & 146 & 95,27 \\
\hline Louis Vuitton I & 600 & 4,625 & 251 & 100,85 & 368 & 100,25 \\
\hline Louis Vuitton II & 750 & 5,000 & 352 & 102,69 & 369 & 100,93 \\
\hline Philips & 750 & 6,125 & - & - & 237 & 104,46 \\
\hline PPR & 800 & 5,250 & 289 & 102,71 & 339 & 98,71 \\
\hline Reed Elsevier & 500 & 5,000 & 208 & 102,68 & - & - \\
\hline Renault & 1.000 & 6,125 & 249 & 104,53 & - & - \\
\hline Repsol YPF & 1.175 & 6,000 & 298 & 105,68 & 358 & 102,02 \\
\hline Reuters & 500 & 4,625 & 229 & 101,23 & - & - \\
\hline Saint Gobain I & 1.000 & 4,750 & 316 & 101,46 & - & - \\
\hline Saint Gobain II & 1.100 & 4,250 & 261 & 99,03 & 384 & 97,11 \\
\hline Saint Gobain III & 1.000 & 5,000 & 337 & 102,55 & 384 & 100,15 \\
\hline Scania & 600 & 3,625 & 219 & 97,36 & - & - \\
\hline Schneider & 900 & 3,125 & - & - & 110 & 96,11 \\
\hline
\end{tabular}


Panel B

\begin{tabular}{|c|c|c|c|c|c|c|}
\hline \multirow[b]{2}{*}{ Issuer } & \multirow{2}{*}{$\begin{array}{r}\text { Amount } \\
\text { issued } \\
\text { (millions of } \\
\text { euros) }\end{array}$} & \multirow[b]{2}{*}{$\begin{array}{r}\text { Coupon } \\
(\%)\end{array}$} & \multicolumn{2}{|c|}{ Nov 2005 - Aug 2007} & \multicolumn{2}{|c|}{ Aug 2007 - June 2009} \\
\hline & & & Obs. & $\begin{array}{c}\text { Mean } \\
\text { Price }\end{array}$ & Obs. & $\begin{array}{r}\text { Mean } \\
\text { Price }\end{array}$ \\
\hline SES & 500 & 3,875 & 52 & 100,78 & 119 & 96,77 \\
\hline Siemens & 2.000 & 5,750 & 72 & 105,55 & 228 & 103,86 \\
\hline Sodexho & 1.000 & 5,875 & 350 & 104,09 & - & - \\
\hline Stora Enso & 500 & 3,250 & 316 & 96,31 & - & - \\
\hline Technip & 650 & 4,625 & 112 & 100,97 & 194 & 98,97 \\
\hline Telecom Italia I & 750 & 4,500 & 300 & 99,88 & 299 & 98,35 \\
\hline Telecom Italia II & 2.000 & 7,250 & 269 & 110,40 & 299 & 104,28 \\
\hline Telefonica & 2.250 & 3,750 & 317 & 97,41 & 272 & 97,89 \\
\hline Telekom Austria & 500 & 3,375 & 137 & 97,40 & 255 & 98,36 \\
\hline Teliasonera & 500 & 3,625 & - & - & 383 & 95,65 \\
\hline Tescol & 750 & 4,750 & 347 & 102,18 & 276 & 100,85 \\
\hline Tesco II & 500 & 3,875 & 303 & 98,67 & 286 & 98,74 \\
\hline Thales & 500 & 4,375 & 111 & 100,17 & 298 & 99,95 \\
\hline Thyssenkrupp & 750 & 5,000 & 235 & 101,73 & 358 & 100,52 \\
\hline Union Fenosa & 500 & 5,000 & 317 & 103,00 & 288 & 100,92 \\
\hline Veolia Environ. & 2.000 & 5,875 & 239 & 103,20 & - & - \\
\hline Vinci & 1.025 & 5,875 & 158 & 104,73 & - & - \\
\hline Vivendi & 630 & 3,625 & 97 & 97,85 & - & - \\
\hline Vodafone & 1.900 & 5,125 & 311 & 100,22 & - & - \\
\hline Volkswagen & 1.000 & 4,125 & 255 & 98,93 & 400 & 98,01 \\
\hline Volvo & 300 & 5,375 & 324 & 103,79 & 327 & 99,86 \\
\hline Average & 942 & 4,788 & 235 & 101,59 & 285 & 99,78 \\
\hline
\end{tabular}

Panel C

\begin{tabular}{|c|c|c|c|c|c|c|c|c|}
\hline \multirow[b]{2}{*}{ Issuer } & \multicolumn{4}{|c|}{ ASP-CDS spreads (b.p.) Nov. 05 - Aug. 07} & \multicolumn{4}{|c|}{ ASP-CDS spreads (b.p.) Aug. 07 - June 09} \\
\hline & Mean & Min & Max & SD & Mean & Min & Max & SD \\
\hline Akzo Nobel I & $-5,89$ & $-20,04$ & 10,21 & 7,43 & 7,26 & $-53,23$ & 117,83 & 35,69 \\
\hline Akzo Nobel II & 3,06 & $-7,51$ & 11,51 & 3,92 & - & - & - & - \\
\hline Altadis & 3,57 & $-14,29$ & 16,19 & 7,09 & - & - & - & - \\
\hline Astrazeneca & - & - & - & - & $-10,19$ & $-86,63$ & 93,67 & 20,74 \\
\hline Auchan & - & - & - & - & 9,55 & $-26,74$ & 101,42 & 27,25 \\
\hline BASF & - & - & - & - & $-27,57$ & $-123,71$ & 21,75 & 25,80 \\
\hline Bayer & - & - & - & - & 22,37 & $-43,90$ & 112,97 & 22,69 \\
\hline Belgacom & - & - & - & - & 5,56 & $-25,12$ & 30,95 & 15,18 \\
\hline BMW & $-1,61$ & $-15,77$ & 8,49 & 3,31 & $-45,20$ & $-356,80$ & 273,54 & 76,37 \\
\hline Bouygues I & 4,41 & $-7,42$ & 13,43 & 4,87 & $-1,10$ & $-58,90$ & 101,42 & 28,11 \\
\hline Bouygues II & $-4,43$ & $-22,81$ & 3,00 & 3,88 & - & - & - & - \\
\hline British AM Tob. I & $-4,61$ & $-26,30$ & 10,90 & 6,65 & - & - & - & - \\
\hline British AM Tob. II & 8,10 & $-7,18$ & 15,10 & 4,04 & 47,36 & $-16,35$ & 202,58 & 44,59 \\
\hline Carrefour I & 2,56 & $-26,95$ & 15,53 & 6,15 & 3,11 & $-50,27$ & 120,18 & 25,26 \\
\hline Carrefour II & $-5,42$ & $-21,84$ & 4,10 & 3,28 & $-16,60$ & $-145,87$ & 73,84 & 31,96 \\
\hline Casino G. P. I & 7,04 & $-27,10$ & 17,56 & 7,46 & 30,20 & $-55,30$ & 170,01 & 42,99 \\
\hline
\end{tabular}


ASP-CDS spreads (b.p.) Nov. 05 - Aug. 07 ASP-CDS spreads (b.p.) Aug. 07 - June 09

\begin{tabular}{|c|c|c|c|c|c|c|c|c|}
\hline \multirow[b]{2}{*}{ Issuer } & & \\
\hline & Mean & Min & Max & SD & Mean & Min & Max & SD \\
\hline Casino G. P. II & 4,66 & $-27,15$ & 16,25 & 7,98 & $-18,42$ & $-315,10$ & 112,15 & 71,18 \\
\hline Casino G. P. III & - & - & - & - & 61,35 & $-31,73$ & 218,98 & 57,14 \\
\hline Compass Group & 8,37 & $-14,26$ & 20,86 & 6,44 & - & - & - & - \\
\hline Edison & 7,03 & $-15,85$ & 15,74 & 3,84 & 16,79 & $-30,09$ & 134,90 & 30,66 \\
\hline Enel & $-2,01$ & $-19,47$ & 5,89 & 4,81 & $-124,83$ & $-656,01$ & 20,97 & 136,64 \\
\hline Energias de & $-0,18$ & $-10,00$ & 7,59 & 4,44 & $-9,78$ & $-71,42$ & 95,40 & 28,60 \\
\hline \multicolumn{9}{|l|}{ Portugal I } \\
\hline Energias de & 1,91 & $-14,88$ & 9,05 & 4,22 & 28,37 & $-72,24$ & 155,44 & 42,72 \\
\hline \multicolumn{9}{|l|}{ Portugal II } \\
\hline E.ON & $-1,41$ & $-9,36$ & 9,08 & 3,24 & - & - & - & - \\
\hline France Telecom I & 3,97 & $-6,25$ & 14,46 & 3,36 & 10,36 & $-64,55$ & 94,61 & 28,52 \\
\hline France Telecom II & 3,97 & $-6,32$ & 7,99 & 2,17 & 22,56 & $-38,73$ & 110,98 & 25,33 \\
\hline France Telecom III & $-7,68$ & $-30,40$ & 0,53 & 6,19 & $-9,41$ & $-79,81$ & 103,03 & 25,32 \\
\hline Iberdrola I & 0,15 & $-11,47$ & 12,10 & 4,40 & $-16,97$ & $-110,50$ & 57,54 & 25,66 \\
\hline Iberdrola II & $-0,93$ & $-8,61$ & 6,31 & 3,18 & - & - & - & - \\
\hline Kingfisher & 0,41 & $-43,52$ & 10,18 & 5,55 & 27,06 & $-130,16$ & 153,20 & 59,81 \\
\hline Louis Vuitton I & 3,78 & $-16,28$ & 13,70 & 4,03 & $-0,59$ & $-86,30$ & 82,79 & 22,17 \\
\hline Louis Vuitton II & 3,22 & $-6,21$ & 10,34 & 2,60 & $-3,58$ & $-91,90$ & 135,19 & 26,22 \\
\hline Philips & - & - & - & - & 5,93 & $-51,09$ & 109,81 & 32,95 \\
\hline PPR & 8,38 & $-23,05$ & 16,78 & 4,92 & $-52,34$ & $-340,83$ & 60,54 & 70,35 \\
\hline Reed Elsevier & $-1,26$ & $-11,96$ & 5,94 & 3,77 & - & - & - & - \\
\hline Renault & 5,43 & $-7,00$ & 21,04 & 3,75 & - & - & - & - \\
\hline Repsol YPF & 5,41 & $-11,79$ & 17,12 & 4,77 & $-7,93$ & $-173,30$ & 110,67 & 47,86 \\
\hline Reuters & 5,67 & $-8,30$ & 15,08 & 3,85 & - & - & - & - \\
\hline Saint Gobain I & $-0,74$ & $-21,91$ & 9,16 & 4,17 & - & - & - & - \\
\hline Saint Gobain II & 4,89 & $-16,54$ & 14,34 & 3,96 & 0,84 & $-122,94$ & 161,76 & 44,82 \\
\hline Saint Gobain III & 3,97 & $-16,68$ & 14,70 & 4,79 & $-31,94$ & $-267,54$ & 101,73 & 55,43 \\
\hline Scania & $-1,17$ & $-19,60$ & 14,03 & 7,88 & - & - & - & - \\
\hline Schneider & - & - & - & - & 1,97 & $-49,42$ & 86,03 & 21,94 \\
\hline SES & 0,42 & $-9,91$ & 5,59 & 3,70 & 44,88 & $-43,05$ & 192,58 & 51,28 \\
\hline Siemens & $-2,48$ & $-10,89$ & 2,56 & 2,45 & $-13,46$ & $-188,60$ & 40,29 & 35,99 \\
\hline Sodexho & 8,92 & $-5,86$ & 15,52 & 3,27 & - & - & - & - \\
\hline Stora Enso & 2,17 & $-33,44$ & 11,16 & 5,54 & - & - & - & - \\
\hline Technip & 9,30 & $-12,92$ & 19,33 & 5,03 & 11,24 & $-167,69$ & 127,37 & 56,59 \\
\hline Telecom Italia I & 2,03 & $-13,60$ & 17,54 & 4,69 & $-25,26$ & $-356,17$ & 84,10 & 78,72 \\
\hline Telecom Italia II & $-0,61$ & $-11,77$ & 18,98 & 5,54 & 31,59 & $-34,29$ & 168,70 & 34,92 \\
\hline Telefonica & 3,37 & $-15,80$ & 12,72 & 3,51 & 4,31 & $-81,50$ & 106,08 & 25,40 \\
\hline Telekom Austria & 1,53 & $-17,34$ & 8,82 & 5,03 & 34,48 & $-31,41$ & 239,45 & 47,33 \\
\hline Teliasonera & - & - & - & - & 32,49 & $-20,96$ & 181,59 & 36,83 \\
\hline Tesco I & 2,64 & $-10,02$ & 12,06 & 4,86 & 3,59 & $-64,70$ & 155,67 & 37,88 \\
\hline Tesco II & 4,08 & $-12,61$ & 13,15 & 3,81 & 3,43 & $-43,35$ & 100,88 & 22,78 \\
\hline
\end{tabular}




\begin{tabular}{|c|c|c|c|c|c|c|c|c|}
\hline \multirow[b]{2}{*}{ Issuer } & \multicolumn{4}{|c|}{ ASP-CDS spreads (b.p.) Nov. 05 - Aug. 07} & \multicolumn{4}{|c|}{ ASP-CDS spreads (b.p.) Aug. 07 - June 09} \\
\hline & Mean & Min & Max & SD & Mean & Min & Max & SD \\
\hline Thales & 4,64 & $-9,70$ & 13,73 & 3,74 & $-4,43$ & $-296,49$ & 73,78 & 59,07 \\
\hline Thyssenkrupp & 1,87 & $-19,24$ & 15,79 & 6,88 & $-72,11$ & $-326,40$ & 80,24 & 89,82 \\
\hline Union Fenosa & 4,32 & $-7,49$ & 10,88 & 3,53 & 12,91 & $-169,00$ & 132,75 & 45,34 \\
\hline Veolia Environ & 0,86 & $-9,87$ & 9,87 & 4,97 & - & - & - & - \\
\hline Vinci & $-0,80$ & $-16,18$ & 9,03 & 4,98 & - & - & - & - \\
\hline Vivendi & 4,66 & $-6,54$ & 18,36 & 4,06 & - & - & - & - \\
\hline Vodafone & $-3,05$ & $-15,04$ & 7,93 & 4,97 & - & - & - & - \\
\hline Volkswagen & 2,40 & $-27,12$ & 11,22 & 5,14 & $-12,70$ & $-151,92$ & 180,09 & 43,70 \\
\hline Volvo & 1,06 & $-17,49$ & 13,48 & 5,48 & 32,44 & $-154,80$ & 378,40 & 82,12 \\
\hline Average & 2,00 & $-15,58$ & 12,04 & 4,68 & 0,17 & $-129,50$ & 125,39 & 43,43 \\
\hline
\end{tabular}

Panel A describes the rating and sector of the CDS and bond issuer. We report the rating at the end of the first subperiod, which spans from November 2005 to August 2007, and at the end of the second subperiod, which covers the subprime crisis and spans from August 2007 to June 2009. Panel B provides descriptive information on the bonds during the first and second subperiods. Panel $\mathrm{C}$ reports descriptive statistics for the basis, which is defined as the difference between ASP and CDS spreads, during the first and second subperiods.

\subsection{Results}

The Panels A and B of Table 3 show the results for the analysis of statistical arbitrage under the UM model during the first and second subperiods, respectively. The sign of parameter $\mu$ for every company in Panel A is in line with the sign of the mean incremental cumulative trading profits with few exceptions (British AM Tob. I and Enel). The unconstrained mean specification is not rejected in most of the cases as the $t$-statistic associated with the parameter $\theta$ reveals. Using the MPR test we find 16(8) persistent anomalies at 5\% confidence level in the period before(during) the crisis in which the basis is persistently negative (the ASP spread is higher than the CDS spread). The results obtained with the other data sources (Reuters, CMA, and JPMorgan) are similar to the ones reported in Table 3 although some small differences exist. ${ }^{20}$ The last column in Panels A and B of Table 3 show the results using the JTTW test. In fact, we find that both the HJTW and the JTTW tests offer similar results. A total of 27 (11) persistent negative bases at $5 \%$ confidence level are found before (during) the crisis. As expected and given the simulation's results, the MPR test seems to be more conservative than JTTW. The differences between both tests are due mainly to the estimators and the corresponding $p$-values associated with restrictions $R_{1}^{c}$ and $R_{2}^{c}$ which are defined in Subsection 2.3. ${ }^{21}$ The UM model usually presents smaller Akaike Information Criteria (AIC)

20 In the period before the crisis, we find an additional persistent negative basis or mispricing using the CMA and the J. P. Morgan databases: Stora Enso. In the crisis period, we find that Edison (Telecom Italia II) does not show mispricings in the Reuters and CMA databases (Reuters and J.P. Morgan databases) but it does in the J. P. Morgan database (CMA database).

21 Our test does not reject the existence of a persistent non-negative basis (no statistical arbitrage) in some cases in which the mean parameter $\mu$ is not significantly different to zero at the $5 \%$ level (France Telecom I, Kingfisher, SES, and Vivendi in the first subperiod, and Casino I and Union Fenosa in the second one). With respect to restriction $R_{2^{\prime}}^{c}$ our test does not find that the rate of growth of the mean, $\mu$, is signifi- 
and Schwarz Information Criteria (SC) than the CM model, suggesting that the former is the most appropriate model. For this reason, we only report the results obtained for the UM model. ${ }^{22}$ We observe that the average of the incremental trading profits, $\Delta v(t)$, is noticeably higher during the subprime crisis. This could lead to the appearance of more potential statistical arbitrage opportunities provided that the deviation between the ASPs and CDSs spreads persists over time. However, the volatility in credit spreads has also increased considerably during the crisis which makes the variance of the incremental trading profits higher and as a consequence, profitable arbitrage opportunities are less likely (because of the non-rejection of the restriction $\left.R_{2}^{c}\right) \cdot{ }^{23}$

Although shorting a corporate bond or ASP is not always a feasible option, for the sake of completeness we also apply the statistical arbitrage test to the strategy based on short positions both in Portfolio I and Portfolio II for the whole sample of entities. We find three additional mispricings during the period before the crisis (Carrefour II, British AM Tob. I, and France Telecom III) in which the basis is persistently positive. There are eight additional mispricings of the same type during the crisis (Astrazeneca, BASF, Enel, France Telecom III, Iberdrola I, PPR, Thyssenkrupp, and Volkswagen). This fact suggests that there are noticeable differences between both subperiods. ${ }^{24}$ Nevertheless, during the crisis the ASPs short sales are less feasible and most costly than under a normal regime. It could prevent investors to exploit potential arbitrage opportunities and then, deviations from the equivalence relation between ASPs and CDSs spreads could persist over time.

During periods of financial distress, the cash-and-carry strategy based on ASPs and CDSs is not completely riskless due to a higher risk of default, to a liquidity premium derived from the uncertainty about ASPs and CDSs' liquidity, to market segmentation, and to funding risk which could affect ASPs and to counterparty risk in CDSs. The influence of the previous aspects could impulse the credit spreads to depart farther from the no-arbitrage relation. We find persistent deviations between credit spreads, based on either long or short risk positions, in $34.8 \%$ of the cases during the crisis. However, it does not mean that these cases in which the bases deviates persistently from zero represent profitable arbitrage opportunities as we show later.

cantly higher than the rate of growth of the variance, $\lambda$, for Akzo Nobel II, Thyssenkrupp, and Volkswagen in the period before the crisis and for Volvo in the crisis period. Indeed, in all these cases, the associated with the difference of the QML parameters $\theta-\lambda$, which is part of the restriction $R_{2}^{C}$ in Subsection 2.3, is not significantly higher than zero at a significance level of $5 \%$. Restriction $R_{2}^{C}$ ensures that the variance of the incremental trading profits, given a potential drop in them, converges to zero. Note that it corroborates the results obtained when we compare the Type I errors of both tests focused on restric$\operatorname{tion} R_{2}^{C}$

22 Detailed results for the statistical arbitrage tests with the CM model and for the AICs and SCs corresponding to the UM and CM models for both subperiods are available upon request.

23 The average increment in the discounted cumulative trading profits is around $€ 72$ in the pre-crisis period and $€ 168$ in the crisis period. These profits present a high deal of variation: $€ 79$ and $€ 403$ on average in the first and second period, respectively. The coefficient of variation for these profits during the crisis doubles the one obtained in the first period.

24 Trapp (2009) finds that during the crisis the short basis (constructed from bond short-sales) becomes relatively more profitable than the long basis (based on bond long positions) compared to the pre-crisis period. 
Panel A

\begin{tabular}{|c|c|c|c|c|c|c|c|c|c|c|c|}
\hline \multirow[b]{2}{*}{ Issuer } & \multicolumn{4}{|c|}{ Parameters } & \multicolumn{4}{|c|}{ t-stat } & \multicolumn{3}{|c|}{ SA } \\
\hline & $\mu$ & $\sigma$ & $\theta$ & $\lambda$ & $\mu$ & $\sigma$ & $\theta$ & $\lambda$ & SA & $p$-value & (JTTW) \\
\hline Akzo Nobel I & $-2 \times 10-3$ & 67,55 & 2,05 & 0,02 & $-0,59$ & 5,05 & 6,53 & 0,50 & No & 0,59 & No \\
\hline Akzo Nobel II & 14,18 & 11,46 & 0,42 & 0,38 & 5,05 & 4,64 & 11,01 & 8,98 & No & 0,35 & Yes*** \\
\hline Altadis & 12,48 & 13,82 & 0,56 & 0,38 & 6,24 & 5,06 & 18,45 & 9,83 & Yes** & 0,04 & Yes*** \\
\hline BMW & $-59,66$ & 37,89 & $-0,25$ & $-0,03$ & $-2,76$ & 4,98 & $-3,00$ & $-0,63$ & No & 1,00 & No \\
\hline Bouygues I & 1,52 & 32,67 & 0,83 & 0,18 & 2,59 & 5,57 & 11,84 & 4,97 & Yes* & 0,06 & Yes $^{* * *}$ \\
\hline Bouygues II & $-82,59$ & 40,11 & $-0,22$ & 0,01 & $-3,63$ & 4,81 & $-3,66$ & 0,14 & No & 1,00 & No \\
\hline British AM Tob. I & 98,68 & 90,79 & $-1,62$ & $-0,03$ & 1,16 & 4,86 & $-1,89$ & $-0,67$ & No & 1,00 & No \\
\hline British AM Tob. II & 54,86 & 40,32 & 0,32 & 0,19 & 4,90 & 5,38 & 7,75 & 4,97 & Yes** & 0,04 & Yes*** \\
\hline Carrefour I & 39,84 & 6,03 & 0,25 & 0,48 & 13,48 & 6,01 & 14,26 & 13,91 & No & 0,92 & No \\
\hline Carrefour II & $-71,84$ & 53,33 & $-0,26$ & $-0,05$ & $-2,66$ & 5,40 & $-3,18$ & $-1,32$ & No & 1,00 & No \\
\hline Casino I & 7,71 & 27,83 & 0,61 & 0,28 & 2,79 & 4,74 & 8,58 & 6,36 & Yes** & 0,02 & Yes*** \\
\hline Casino II & 3,32 & 28,60 & 0,70 & 0,26 & 2,22 & 7,01 & 8,57 & 9,44 & Yes*** & 0,00 & Yes*** \\
\hline Compass Group & 3,37 & 52,32 & 0,70 & 0,17 & 1,88 & 7,16 & 7,25 & 6,15 & Yes** & 0,04 & Yes*** \\
\hline Edison & 2,71 & 12,80 & 0,87 & 0,34 & 6,56 & 6,52 & 31,78 & 11,30 & Yes*** & 0,00 & Yes*** \\
\hline Enel & 0,00 & 14,79 & 4,42 & 0,23 & 0,00 & 3,62 & 53,93 & 8,23 & No & 0,86 & No \\
\hline Energias de Portugal I & $-74,31$ & 36,63 & $-0,23$ & $-0,01$ & $-3,59$ & 4,86 & $-3,61$ & $-0,12$ & No & 1,00 & No \\
\hline Energias de Portugal II & $-68,21$ & 47,46 & $-0,31$ & $-0,02$ & $-2,49$ & 5,34 & $-3,23$ & $-0,45$ & No & 1,00 & No \\
\hline E.ON & $-37,51$ & 40,50 & $-0,13$ & $-0,03$ & $-2,33$ & 5,62 & $-1,44$ & $-0,82$ & No & 1,00 & No \\
\hline France Telecom I & 0,27 & 11,86 & 1,22 & 0,28 & 1,45 & 5,48 & 8,24 & 6,44 & No & 0,10 & Yes*** \\
\hline France Telecom II & 11,14 & 5,03 & 0,40 & 0,49 & 4,89 & 3,71 & 7,47 & 7,14 & No & 0,50 & No \\
\hline France Telecom III & $-330,98$ & 73,33 & $-0,81$ & $-0,03$ & $-4,25$ & 5,26 & $-4,86$ & $-0,67$ & No & 1,00 & No \\
\hline Iberdrola I & $-58,25$ & 33,35 & $-0,23$ & $-0,02$ & $-3,63$ & 5,15 & $-3,79$ & $-0,59$ & No & 1,00 & No \\
\hline Iberdrola II & $-57,61$ & 27,08 & $-0,15$ & 0,04 & $-4,51$ & 4,43 & $-3,16$ & 0,76 & No & 1,00 & No \\
\hline Kingfisher & 1,57 & 27,82 & 0,63 & 0,14 & 1,35 & 5,38 & 4,70 & 3,88 & Yes* & 0,08 & Yes*** \\
\hline Louis Vuitton I & 57,60 & 50,72 & 0,20 & 0,06 & 4,70 & 4,99 & 4,52 & 1,37 & Yes** & 0,04 & Yes $^{* * *}$ \\
\hline Louis Vuitton II & 1,18 & 26,05 & 0,87 & 0,15 & 3,17 & 6,33 & 15,57 & 4,98 & Yes $^{* *}$ & 0,05 & Yes $^{* * *}$ \\
\hline PPR & 3,94 & 20,21 & 0,83 & 0,29 & 5,51 & 5,50 & 24,84 & 8,07 & Yes ${ }^{* * *}$ & 0,00 & Yes*** \\
\hline Reed Elsevier & $-48,31$ & 54,90 & $-0,06$ & $-0,05$ & $-3,20$ & 5,28 & $-0,97$ & $-1,19$ & No & 1,00 & No \\
\hline Renault & 11,75 & 19,38 & 0,55 & 0,24 & 6,37 & 5,19 & 18,38 & 6,14 & Yes** & 0,02 & Yes*** \\
\hline Repsol YPF & 0,71 & 13,99 & 1,03 & 0,36 & 3,15 & 7,49 & 18,27 & 14,02 & Yes** & 0,02 & Yes*** \\
\hline Reuters & 0,52 & 8,99 & 1,03 & 0,41 & 2,56 & 7,21 & 14,79 & 15,39 & Yes** $^{* *}$ & 0,04 & Yes $^{* * *}$ \\
\hline Saint Gobain I & 4,36 & 8,76 & $-1,46$ & 0,36 & 0,52 & 6,30 & $-0,92$ & 11,75 & No & 1,00 & No \\
\hline Saint Gobain II & 46,42 & 20,30 & 0,28 & 0,23 & 7,81 & 6,01 & 10,89 & 7,03 & Yes** & 0,05 & Yes** \\
\hline Saint Gobain III & 0,49 & 15,38 & 1,07 & 0,30 & 3,41 & 5,51 & 20,87 & 8,72 & No & 0,13 & Yes*** \\
\hline Scania & $-68,78$ & 75,84 & $-0,29$ & $-0,09$ & $-1,86$ & 5,46 & $-2,50$ & $-2,44$ & No & 1,00 & No \\
\hline SES & 0,22 & 4,49 & 0,71 & 0,32 & 0,88 & 6,87 & 3,37 & 11,28 & No & 0,10 & Yes*** \\
\hline Siemens & $-0,43$ & 5,99 & 0,65 & 0,28 & $-0,82$ & 4,81 & 2,69 & 6,34 & No & 0,95 & No \\
\hline Sodexho & 6,52 & 41,16 & 0,76 & 0,15 & 6,64 & 6,53 & 28,16 & 5,16 & Yes** & 0,03 & Yes*** \\
\hline Stora Enso & 0,29 & 9,84 & 1,08 & 0,35 & 2,68 & 5,36 & 16,63 & 9,88 & No & 0,17 & Yes*** \\
\hline Technip & 16,92 & 39,30 & 0,43 & 0,23 & 2,78 & 5,09 & 6,13 & 5,75 & Yes** & 0,02 & Yes*** $^{* *}$ \\
\hline Telecom Italia I & $-4,47$ & 14,91 & 0,24 & 0,20 & $-1,37$ & 4,45 & 1,67 & 4,45 & No & 1,00 & No \\
\hline Telecom Italia II & $-3 \times 10-4$ & 32,82 & 2,17 & 0,19 & $-0,41$ & 5,46 & 4,97 & 5,15 & No & 0,58 & No \\
\hline Telefonica & 0,36 & 10,71 & 1,09 & 0,35 & 2,91 & 5,54 & 17,72 & 9,76 & No & 0,17 & Yes*** \\
\hline Telekom Austria & $-43,98$ & 70,42 & $-0,13$ & $-0,05$ & $-1,63$ & 5,86 & $-1,02$ & $-1,47$ & No & 1,00 & No \\
\hline Tescol & $-78,92$ & 40,38 & $-0,26$ & $-1 \times 10-3$ & $-3,37$ & 5,29 & $-3,81$ & $-0,03$ & No & 1,00 & No \\
\hline Tesco II & 6,96 & 22,14 & 0,63 & 0,16 & 6,85 & 6,74 & 23,46 & 5,39 & Yes*** & 0,00 & Yes $^{* * *}$ \\
\hline Thales & 48,80 & 26,02 & 0,09 & 0,20 & 4,06 & 4,67 & 1,67 & 4,39 & No & 0,63 & No \\
\hline Thyssenkrupp & 18,67 & 17,40 & 0,36 & 0,35 & 4,18 & 4,45 & 7,61 & 7,69 & No & 0,53 & No \\
\hline Union Fenosa & 0,55 & 19,32 & 1,01 & 0,26 & 2,74 & 6,79 & 15,69 & 9,12 & No & 0,24 & Yes $^{* * *}$ \\
\hline Veolia Environ. & $-39,40$ & 44,15 & $-0,01$ & $-0,03$ & $-3,60$ & 5,59 & $-0,25$ & $-0,74$ & No & 1,00 & No \\
\hline Vinci & $-0,42$ & 8,50 & 0,71 & 0,35 & $-0,92$ & 5,03 & 3,60 & 9,00 & No & 0,94 & No \\
\hline Vivendi & 0,94 & 9,68 & 0,77 & 0,36 & 1,58 & 6,58 & 6,66 & 12,37 & No & 0,11 & Yes*** \\
\hline Vodafone & $-2 \times 10-7$ & 2,18 & 3,44 & 0,60 & $-0,49$ & 3,92 & 9,70 & 11,81 & No & 0,47 & No \\
\hline Volkswagen & 17,07 & 17,09 & 0,38 & 0,27 & 4,66 & 6,74 & 8,81 & 9,00 & No & 0,11 & Yes $^{* * *}$ \\
\hline Volvo & $-6,68$ & 40,84 & 0,25 & $-0,01$ & $-1,94$ & 5,89 & 2,68 & $-0,38$ & No & 1,00 & No \\
\hline
\end{tabular}




\begin{tabular}{|c|c|c|c|c|c|c|c|c|c|c|c|}
\hline \multirow[b]{2}{*}{ Issuer } & \multicolumn{4}{|c|}{ Parameters } & \multicolumn{4}{|c|}{ t-stat } & \multicolumn{2}{|r|}{ SA } & \multirow{2}{*}{$\begin{array}{r}\text { SA } \\
\text { (JTTW) }\end{array}$} \\
\hline & $\mu$ & $\sigma$ & $\theta$ & $\lambda$ & $\mu$ & $\sigma$ & $\theta$ & $\lambda$ & SA & $p$-value & \\
\hline Akzo Nobel I & $-238,73$ & 67,18 & $-0,53$ & $-0,01$ & $-3,89$ & 5,38 & $-6,08$ & $-0,15$ & No & 1,00 & No \\
\hline Astrazeneca & $-0,25$ & 82,09 & 0,93 & 0,13 & $-0,44$ & 5,26 & 2,32 & 3,48 & No & 0,67 & $\mathrm{~N}$ \\
\hline Auchan & $-157,36$ & 14,62 & $-1,17$ & 0,58 & $-10,74$ & 8,06 & $-3,69$ & 25,18 & No & 1,00 & $\mathrm{Nc}$ \\
\hline BASF & $-76,46$ & 65,90 & $-0,30$ & $-0,05$ & $-1,99$ & 6,12 & $-2,71$ & $-1,68$ & No & 1,00 & No \\
\hline Bayer & 4,12 & 17,32 & 0,92 & 0,58 & 2,55 & 5,18 & 13,09 & 15,83 & Yes** & 0,04 & Yes*** \\
\hline Belgacom & 4,65 & 11,35 & 0,40 & 0,44 & 1,72 & 3,94 & 3,58 & 9,06 & No & 0,53 & No \\
\hline BMW & $-198,15$ & 71,26 & $-0,44$ & $-0,01$ & $-3,35$ & 5,47 & $-5,33$ & $-0,43$ & No & 1,00 & Nc \\
\hline Bouygues I & 10,91 & 21,76 & 0,36 & 0,51 & 1,88 & 7,04 & 3,53 & 19,21 & No & 0,65 & $\mathrm{~N}$ \\
\hline British AM Tob. II & 0,69 & 11,45 & 1,35 & 0,74 & 2,59 & 8,38 & 20,07 & 33,28 & Yes $^{* *}$ & 0,03 & Yes*** \\
\hline Carrefour I & $-70,70$ & 69,77 & $-0,21$ & $-0,05$ & $-2,09$ & 5,97 & $-2,17$ & $-1,46$ & No & 1,00 & No \\
\hline Carrefour II & $-91,26$ & 69,85 & $-0,20$ & $-0,02$ & $-2,48$ & 5,60 & $-2,41$ & $-0,73$ & No & 1,00 & No \\
\hline Casino I & 0,15 & 10,45 & 1,45 & 0,75 & 0,92 & 7,30 & 7,74 & 29,21 & No & 0,16 & Yes** \\
\hline Casino II & 0,00 & 4,06 & 2,65 & 0,41 & $-0,34$ & 5,93 & 5,42 & 12,82 & No & 0,67 & No \\
\hline Casino III & 1,08 & 21,69 & 1,22 & 0,64 & 2,05 & 7,23 & 14,37 & 24,51 & Yes** & 0,05 & Yes*** \\
\hline Edison & 1,36 & 32,40 & 1,09 & 0,52 & 1,83 & 8,14 & 11,38 & 22,79 & Yes** & 0,05 & Yes*** \\
\hline Enel & $-82,74$ & 116,84 & $-0,24$ & $-0,07$ & $-1,42$ & 6,40 & $-1,67$ & $-2,28$ & No & 1,00 & No \\
\hline Energias de Portugal I & $-66,19$ & 98,89 & $-0,12$ & $-0,01$ & $-1,75$ & 5,64 & $-1,08$ & $-0,35$ & No & 1,00 & No \\
\hline Energias de Portugal II & $-82,64$ & 96,30 & $-0,23$ & $-0,06$ & $-1,72$ & 6,28 & $-2,03$ & $-1,93$ & No & 1,00 & No \\
\hline France Telecom I & 72,24 & 43,58 & $-0,38$ & 0,37 & 2,36 & 5,35 & $-2,51$ & 10,51 & No & 1,00 & No \\
\hline France Telecom II & 23,22 & 15,56 & 0,57 & 0,61 & 4,01 & 5,63 & 11,74 & 18,07 & No & 0,55 & No \\
\hline France Telecom III & $-104,98$ & 74,34 & $-0,25$ & $-0,04$ & $-2,50$ & 5,73 & $-2,92$ & $-1,06$ & No & 1,00 & No \\
\hline |berdrola I & $-89,98$ & 78,76 & $-0,24$ & $-0,04$ & $-2,14$ & 5,80 & $-2,42$ & $-1,27$ & No & 1,00 & No \\
\hline Kingfisher & 0,00 & 15,45 & 2,30 & 0,74 & 0,25 & 5,86 & 3,14 & 21,39 & No & 0,46 & No \\
\hline Louis Vuitton I & $-11,53$ & 16,33 & $-0,94$ & 0,63 & $-0,76$ & 5,99 & $-1,05$ & 19,99 & No & 1,00 & No \\
\hline Louis Vuitton II & $-176,41$ & 23,14 & $-0,79$ & 0,51 & $-8,16$ & 5,18 & $-4,74$ & 13,82 & No & 1,00 & No \\
\hline Philips & $-80,45$ & 82,09 & $-0,43$ & 0,09 & $-1,39$ & 5,25 & $-2,15$ & 2,42 & No & 1,00 & No \\
\hline PPR & $-135,61$ & 79,49 & $-0,57$ & 0,22 & $-2,20$ & 6,17 & $-2,64$ & 7,30 & No & 1,00 & No \\
\hline Repsol YPF & 3,90 & 11,75 & 0,68 & 0,75 & 1,73 & 8,53 & 6,28 & 34,31 & No & 0,44 & No \\
\hline Saint Gobain II & 29,38 & 16,66 & 0,32 & 0,65 & 3,73 & 6,11 & 5,31 & 21,15 & No & 0,93 & No \\
\hline Saint Gobain III & 0,00 & 52,84 & 2,12 & 0,40 & $-0,31$ & 5,68 & 3,95 & 12,07 & No & 1,00 & No \\
\hline Schneider & 11,01 & 18,70 & 0,32 & 0,48 & 1,82 & 4,50 & 2,87 & 11,39 & No & 0,64 & No \\
\hline SES & 0,26 & 2,86 & 1,36 & 0,94 & 2,18 & 6,67 & 13,82 & 33,24 & Yes** & 0,05 & Yes*** \\
\hline Siemens & $-166,11$ & 71,49 & $-0,41$ & $-0,02$ & $-2,97$ & 5,55 & $-4,70$ & $-0,66$ & No & 1,00 & No \\
\hline Technip & 3,82 & 3,54 & 0,85 & 0,93 & 3,76 & 5,34 & 16,54 & 26,17 & No & 0,80 & No \\
\hline Telecom Italia I & 72,40 & 9,96 & 0,07 & 0,85 & 8,74 & 8,02 & 1,07 & 36,51 & No & 1,00 & No \\
\hline Telecom Italia II & 16,25 & 21,86 & 0,71 & 0,56 & 3,39 & 6,55 & 13,01 & 21,43 & Yes** & 0,05 & Yes ${ }^{* * *}$ \\
\hline Telefonica & 24,20 & 13,19 & 0,42 & 0,60 & 4,56 & 7,18 & 9,36 & 22,94 & No & 0,76 & No \\
\hline Telekom Austria & 0,21 & 2,23 & 1,47 & 1,04 & 2,11 & 7,49 & 17,59 & 41,54 & Yes** & 0,05 & Yes*** \\
\hline Teliasonera & 7,01 & 9,26 & 0,92 & 0,70 & 6,60 & 24,42 & 69,97 & 7,44 & Yes** & 0,04 & Yes*** \\
\hline Tescol & $-128,68$ & 5,52 & $-0,24$ & 0,81 & $-25,52$ & 6,76 & $-6,23$ & 29,18 & No & 1,00 & No \\
\hline Tesco II & $-108,21$ & 15,23 & $-0,48$ & 0,58 & $-8,25$ & 6,99 & $-5,20$ & 21,55 & No & 1,00 & No \\
\hline Thales & $-32,44$ & 49,43 & $-0,07$ & $-0,01$ & $-2,06$ & 5,81 & $-0,76$ & $-0,46$ & No & 1,00 & No \\
\hline Thyssenkrupp & $-69,91$ & 86,34 & $-0,19$ & $-0,05$ & $-1,83$ & 5,92 & $-1,73$ & $-1,49$ & No & 1,00 & No \\
\hline Union Fenosa & 0,40 & 33,52 & 1,29 & 0,53 & 1,35 & 7,03 & 10,09 & 19,71 & No & 0,12 & Yes*** \\
\hline Volkswagen & $-83,03$ & 56,11 & $-0,24$ & $-0,03$ & $-2,80$ & 5,85 & $-3,16$ & $-0,79$ & No & 1,00 & No \\
\hline Volvo & 10,22 & 62,75 & 0,30 & 0,27 & 1,18 & 5,96 & 2,16 & 8,57 & No & 0,25 & Yes $^{* *}$ \\
\hline
\end{tabular}

Panel A describes the rating and sector of the CDS and bond issuer. We report the rating at the end of the first subperiod, which spans from November 2005 to August 2007, and at the end of the second subperiod, which covers the subprime crisis and spans from August 2007 to June 2009. Panel B provides descriptive information on the bonds during the first and second subperiods. Panel $\mathrm{C}$ reports descriptive statistics for the basis, which is defined as the difference between ASP and CDS spreads, during the first and second subperiods. 
Table 4 shows the number of investment days, the probability of a loss defined as the ratio between the number of days with losses and the total number of investment days, the Fisher's skewness of the payments when these are below the percentile $33 \%$ and the minimum level of funding, trading or other types of costs that if taken into account may make non-profitable the persistent mispricings found with the MPR test and the HJTW/JTTW tests, respectively. The firms for which this information is reported are the ones in which either HJTW/JTTW tests or ours find a persistent negative basis. Attending to HJTW/JTTW tests all the cases reported have a persistent negative basis while the cases in which such persistent negative basis is found using the MPR test are represented in boldface. We observe that the number of investment days in the cases in which the basis is persistently negative presents a high deal of variation. As one of the statistical arbitrage conditions states that investors are only concerned about the variance of a potential decrease in wealth, we show a measure of the downside risk in the payments and more specifically, a measure of the downside risk in the losses or lower payments. This measure is the skewness of the payments below the percentile $33 \%$ and reflects the fact that the investors could be adverse to negative skewness. In Figure 1 we show Fisher's skewness as defined above to clarify the economic difference between the MPR test and the JTTW test. Before the crisis and using the MPR test, all the potential statistical arbitrage opportunities have positive skewness except in one case (0.04). On the other hand, the potential arbitrage opportunities discarded by the MPR test but accepted by the JTTW test all have negative skewness ranging from $(-0.08,-2.36)$. During the crisis and using our test, all the potential statistical arbitrage opportunities have positive skewness except in one case $(0.05)$. On the other hand, the potential arbitrage opportunities discarded by the MPR test but accepted by the JTTW test all have negative skewness ranging from $(-1.45,-2.24)$. Therefore, as explained in Sec-

Fisher's skewness of the payments below the percentile $33 \%$
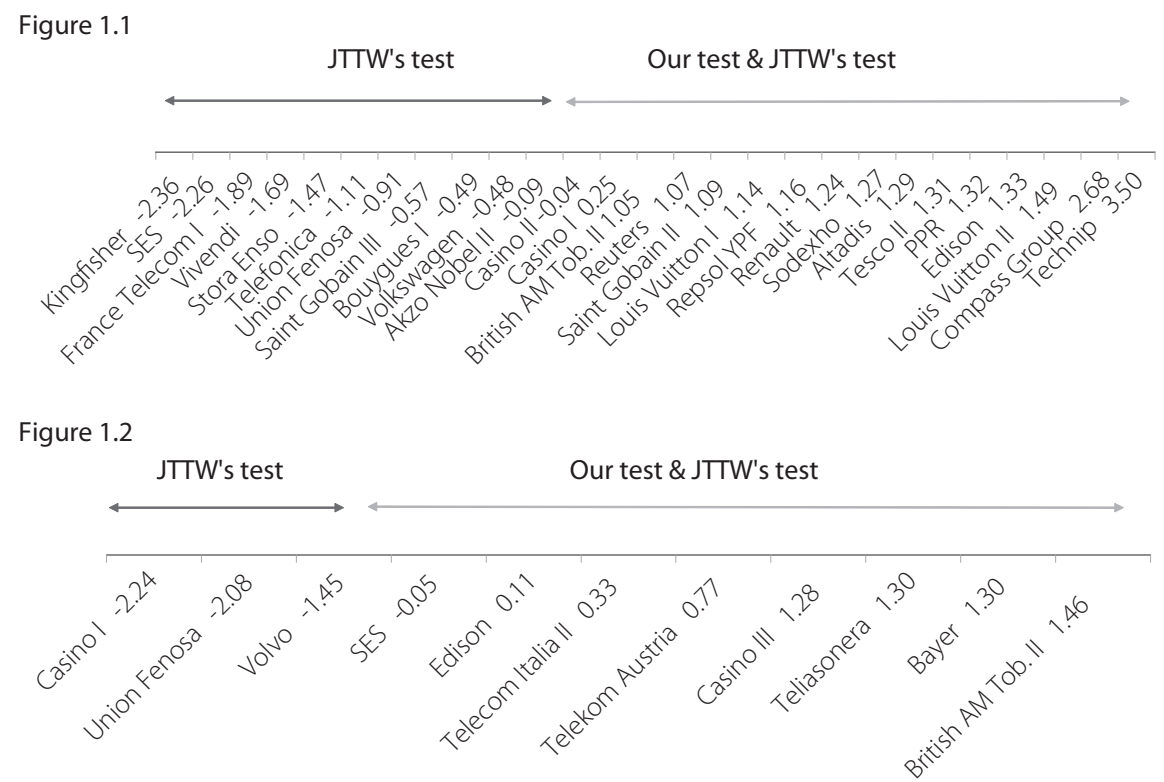

This figure shows the Fisher's skewness of the payments when these are below the percentile 33\%. Figure 1.1 shows the Fisher's skewness for the arbitrage opportunities detected by the MPR test and by the JTTW test before the crisis. Figure 1.2 shows the Fisher's skewness for the arbitrage opportunities detected by the MPR test and by the JTTW test during the crisis. 
tion 3 there is a relevant economic difference between the JTTW test and the MPR test. Arbitrageurs engaging in arbitrage opportunities detected by the JTTW test (but not detected by our test) are exposed inadvertently to significant downside risk that is even more extreme during the crisis period.

Before the crisis, HJTW and JTTW tests find persistent negative bases in eleven cases in which the MPR test rejects the existence of such persistent deviations (the cases in which our test finds persistent deviations are in boldface). Most of the cases in which the MPR test does not find potential statistical arbitrage opportunities correspond to cases with high probabilities of a loss: Bouygues I, France Telecom I, Kingfisher, Saint Gobain III, SES, Stora Enso, Telefonica, Union Fenosa, and Vivendi. Besides the previous nine cases, Akzo Nobel II does not fulfill the restriction $R_{2}^{c}$ and Volkswagen has a significant and negative skewness. Regarding the crisis period, HJTW and JTTW tests find three persistent negative bases more than the MPR test: Casino I, Union Fenosa, and Volvo. In all three cases the probability of a loss is higher than $20 \%$ and moreover they have a remarkable negative skewness.

The previous results ignore any of the funding or trading costs involved in entering the trade in the real world. For this reason, we cannot assure that the mispricings we find are profitable statistical arbitrage opportunities. One of these market frictions is the funding cost. Although during the period prior to the crisis funding costs were quite low (about 1-3 basis points for AAA-rated reference entities), the situation changes after the summer of 2007 and funding costs increases significantly. Funding costs are a function of the investor credit quality and of the credit quality of the underlying instrument (e.g. investment grade vs. high yield). Elizalde and Doctor (2009) denote investors who have access to cheap credit as banks and investors who are required to pay higher levels of funding as hedge funds. Elizalde and Doctor (2009) estimations for the banks and hedge funds costs of funding long risk positions in bonds for a typical investment grade bond are: 6 / 25 b.p. in July 2008, 51 / 101 b.p. in October 2008 and 14 / 44 b.p. in July 2009. Elizalde and Doctor (2009) funding costs estimations refer to specific months and they are not available for the pre-crisis period. Due to the difficulty for obtaining data on institutional level funding constraints, we use as in Acharya, Schaefer and Zhang (2006) the spread between financial commercial paper and T-bill rates as a proxy for the funding costs faced by financial intermediaries. Concretely, we proxy them by means of the difference between the 90-days US AA-rated commercial paper interest rates for the financial companies and the 90-days US T-bill. This proxy represents the financing costs for an AA-rated financial investor. The average funding costs from November 1st, 2005 to August 8th, 2007 attending to the previous specification are 35 basis points. These costs increased significantly during the crisis period (August 9th, 2007 - June 29th, 2009) to 110 basis points.

In addition to funding costs, the trading costs also affect the investment strategy and their effect should have increased during the crisis. We employ the quote-level data to answer this question and add the trading costs, which are measured by means of the bid-ask spread, to the strategy's profits. Even ignoring the existence of funding costs, the persistent negative deviations in the basis are not profitable during the crisis if trading costs are included. Before the crisis, we find that the number of the persistent negative deviations in the basis decreases to nine: Altadis, British AM Tob. II, Compass Group, Edison, PRR, Renault, Saint Gobain II, Sodexho, and 
Tesco II. If one considers jointly trading and funding costs the number of profitable persistent mispricings is probably zero.

In the cases in which the MPR test does not find a persistent negative basis, the HJTW/JTTW tests find that this persistent deviation exists even when the strategy's costs are equal or lower than 3 or 4 b.p. before the crisis and 3, 4, or 5 b.p. during the crisis, depending on the case which one considers.

We find that when the annualized average funding cost associated to each investment during the period before the crisis is greater than 2 b.p., the negative persistent basis is not profitable in British AM Tob. II, Louis Vuitton I and II, Repsol YPF, Reuters, Saint Gobain II, and Technip. Using HJTW/JTTW tests, the same cases present a profitable persistent negative basis for costs up to 3.6 b.p., on average. When the transaction costs are greater than 3 b.p., no profitable persistent mispricing is found in Altadis, Casino I and II, and Compass Group using the MPR test while the average limit costs compatible with the absence of persistent mispricings in the other tests for the same four examples is 5.25 b.p. The same pattern is observed in Edison, Renault, PPR, Tesco II, and Sodexho in which the average difference in the costs compatible with the absence of profitable negative bases found by both types of tests is, on average, equal to 2 b.p. being the lowest limit costs the corresponding to the MPR test. ${ }^{25}$ According to the proxy for the institutional investors funding costs we conclude that the mispricings observed in CDS and ASP markets are not statistical arbitrage opportunities for any of the two types of tests being ours the most conservative.

The discrepancies measured in basis points between the MPR and the HJTW/JTTW tests when finding persistent negative deviations in the basis increases during the crisis period. If the annualized average funding cost associated to each investment during the crisis is greater than 1 b.p., the profitable persistent negative basis disappears in SES, Telecom Italia II, and Telekom Austria when one uses the MPR test while using the alternative tests the same profitable persistent deviation disappears when the cost is higher than 5,11 , and 7 b.p., respectively for the three previous examples. When the strategy's cost is greater than 2 b.p. (3 b.p.), the persistent negative basis disappears in Casino III and Edison (Bayer, British AM. Tob. II, and Teliasonera)while using the other tests the same persistent deviation disappears when the cost is higher than 9 and 8 b.p. $(8,10$, and 11 b.p.), respectively for the two (three) previous examples. According to the funding costs of the long risk positions estimated by Elizalde and Doctor (2009) and regarding the proxy for the funding cost faced by financial intermediaries, we conclude that no statistical arbitrage opportunity remains during the crisis. As in the pre-crisis period, the MPR test is more conservative than HJTW/JTTW tests.

These results suggest the following conclusions. First, in the short-run the basis could temporarily deviate from zero to a considerable extent. Second, there are also

25 We are considering average constant funding costs for the corresponding period although it is likely that an investor would have to renew their funding at regular intervals and so would be somewhat exposed to changes in the levels of funding. To have a better perspective of these average costs, the average ASP, bond, and CDS spread during the period before the crisis is around 25 b.p. and, so, a cost of 3 b.p. is around $12 \%$ of the credit spread. 
in some cases persistent (positive and negative) deviations of the basis which suggests that the arbitrage forces find some obstacles, probably related with transaction costs. In sum, although some persistent mispricings in credit spreads are found, they are unlikely to be profitable statistical arbitrage opportunities.

\section{Understanding the Persistent Mispricings}

Panel A

\begin{tabular}{|c|c|c|c|c|c|}
\hline Issuer & $\begin{array}{r}\text { Number of } \\
\text { investment days }\end{array}$ & $\begin{array}{l}\text { Days with } \\
\text { losses (\%) }\end{array}$ & $\begin{array}{l}\text { Skewness } \\
\text { (pctl } 33 \text { of } \\
\text { payments) }\end{array}$ & $\begin{array}{r}\text { Minimum level } \\
\text { of costs using } \\
\text { MPR test }\end{array}$ & $\begin{array}{r}\text { Minimum level } \\
\text { of costs using } \\
\text { HJTW/JTTW } \\
\text { tests }\end{array}$ \\
\hline Akzo Nobel II & 344 & 5,52 & $-0,09$ & 0 & 3 \\
\hline Altadis & 300 & 0,33 & $1.29 *$ & 3 & 7 \\
\hline Bouygues I & 197 & 10,66 & $-0,49$ & 0 & 3 \\
\hline British AM Tob. II & 232 & 0,00 & $1.05^{*}$ & 2 & 3 \\
\hline Casino I & 148 & 4,73 & 0,25 & 3 & 6 \\
\hline Casino II & 196 & 7,65 & $-0,04$ & 3 & 4 \\
\hline Compass Group & 121 & 0,83 & $2.68^{*}$ & 3 & 4 \\
\hline Edison & 339 & 0,29 & $1.33^{*}$ & 4 & 6 \\
\hline France Telecom I & 119 & 9,24 & $-1,89$ & 0 & 4 \\
\hline Kingfisher & 270 & 19,20 & $-2,36$ & 0 & 3 \\
\hline Louis Vuitton I & 251 & 1,20 & $1.14^{*}$ & 2 & 3 \\
\hline Louis Vuitton II & 345 & 3,19 & $1.49 *$ & 2 & 4 \\
\hline PPR & 289 & 2,08 & $1.32^{*}$ & 5 & 7 \\
\hline Renault & 249 & 0,80 & $1.24^{*}$ & 4 & 7 \\
\hline Repsol YPF & 298 & 4,36 & $1.16^{*}$ & 2 & 4 \\
\hline Reuters & 229 & 2,18 & $1.07^{*}$ & 2 & 4 \\
\hline Saint Gobain II & 261 & 0,38 & $1.09 *$ & 2 & 3 \\
\hline Saint Gobain III & 348 & 8,62 & $-0,57$ & 0 & 3 \\
\hline SES & 52 & 34,62 & $-2,26$ & 0 & 3 \\
\hline Sodexho & 350 & 0,00 & $1.27^{*}$ & 7 & 9 \\
\hline Stora Enso & 250 & 13,20 & $-1,47$ & 0 & 3 \\
\hline Technip & 112 & 0,00 & $3.50 *$ & 2 & 4 \\
\hline Telefonica & 317 & 8,52 & $-1,11$ & 0 & 3 \\
\hline Tesco II & 250 & 0,00 & $1.31 *$ & 5 & 6 \\
\hline Union Fenosa & 250 & 13,20 & $-0,91$ & 0 & 3 \\
\hline Vivendi & 97 & 8,25 & $-1,69$ & 0 & 3 \\
\hline Volkswagen & 256 & 5,08 & $-0,48$ & 0 & 3 \\
\hline
\end{tabular}




\begin{tabular}{|c|c|c|c|c|c|}
\hline Issuer & $\begin{array}{r}\text { Number of } \\
\text { investment days }\end{array}$ & $\begin{array}{l}\text { Days with } \\
\text { losses (\%) }\end{array}$ & $\begin{array}{l}\text { Skewness } \\
\text { (pctl } 33 \text { of } \\
\text { payments) }\end{array}$ & $\begin{array}{r}\text { Minimum level } \\
\text { of costs using } \\
\text { MPR test }\end{array}$ & $\begin{array}{r}\text { Minimum level } \\
\text { of costs using } \\
\text { HJTW/JTTW } \\
\text { tests }\end{array}$ \\
\hline Bayer & 347 & 3,170 & $1.30^{*}$ & 3 & 8 \\
\hline British AM Tob. II & 300 & 1,667 & $1.46^{*}$ & 3 & 10 \\
\hline Casino G. P. I & 200 & 23,047 & $-2,24$ & 0 & 4 \\
\hline Casino G. P. III & 231 & 5,628 & $1.28^{*}$ & 2 & 9 \\
\hline Edison & 338 & 8,000 & 0,11 & 2 & 8 \\
\hline SES & 119 & 9,061 & $-0,05$ & 1 & 5 \\
\hline Telecom Italia II & 299 & 5,686 & $0.33^{*}$ & 1 & 11 \\
\hline Telekom Austria & 250 & 5,600 & $0.77^{*}$ & 1 & 7 \\
\hline Teliasonera & 250 & 0,667 & $1.30 *$ & 3 & 11 \\
\hline Union Fenosa & 250 & 23,600 & $-2,08$ & 0 & 5 \\
\hline Volvo & 150 & 37,333 & $-1,45$ & 0 & 3 \\
\hline
\end{tabular}

This table reports additional information on the number of investment days, days with losses, skewness and transaction costs. This table splits into two panels. Panel A refers to the period before the crisis (November 2005 - August 2007) while Panel B corresponds to the crisis period (August 2007 - June 2009). The first column of each panel reports the number of investment days. The second column shows the probability of a loss in percentage terms, which is defined as the ratio between the number of days with losses and the total number of investment days. The third column reports the Fisher's skewness of the payments obtained by the investor when these payments are below the percentile 33\% (pctl 33). The symbol * denotes that the skewness of the payments below the percentile $33 \%$ is significantly positive at $5 \%$ level. The fourth and fifth columns show the minimum level of funding, trading or other types of transaction costs that make non-profitable the persistent mispricing found with our test (MPR) and the HJTW/JTTW tests, respectively. The firms for which this information is reported are the ones in which either the HJTW/JTTW tests or the MPR find a persistent positive basis. In boldface are the statistical arbitrage opportunities detected by the MPR test.

\subsection{Robustness tests and extensions}

In this section, we perform some robustness tests and extensions. We comment the results under the model that best fits the data according to AIC and SC. Under all the new specifications, test and extensions we find that there are not statistical arbitrage opportunities once we consider the effect of the trading and funding costs. For this reason, we focus on how the new alternatives affect to the existence of persistent negative bases ignoring the previous market frictions.

\subsubsection{Closing positions}

The investor positions were not closed in the previous analysis since future losses are perfectly known at the current moment if no default occurs. CDSs transfer credit risk from one party to another and it is possible that the investors only want exposure to risk for a limited period of time. These investors could liquidate their positions at a given price if there is an adequate level of liquidity in this OTC market. Thus, we analyze the same strategy but closing, every 45 days, any investment made during that period under the assumption that both CDSs and ASPs positions can be 
closed at the same time. ${ }^{26}$ Positions are closed whenever the basis is positive $\left(s_{t}^{A}<\bar{s}_{t}\right)$ to avoid closing positions at dates when an important and certain loss would take place. If the basis is negative $\left(s_{t}^{A}>\bar{s}_{t}\right)$ at a given date, the positions will be closed on the first subsequent date when it is positive. However, if investors close a high number of positions at a given date, it would lead to a large payment a quarter after that date which is derived from the closed positions. It affects the mean and variance growth rates. Ignoring funding and trading costs, the number of persistent negative bases before the crisis increases to 18 (the 16 opportunities reported in Panel A of Table 3 plus Bouygues I and Stora Enso). Nevertheless, we find the same nine mispricings during the crisis.

\subsubsection{Trading days and CDS prices analysis}

The investment strategy is implemented whenever there is an adequate grade of liquidity according to the information on transaction prices. However, we repeat the analysis ignoring this restriction and assume that the investments are implemented every day. For this aim, we employ quotes from CMA, Reuters, J.P. Morgan, and the Fenics curve from GFI. In the first subperiod, we find the same persistent negative bases that are reported in Panel A of Table 3 and other five additional mispricings. The additional mispricings are common to CMA, J.P. Morgan, and Fenics (GFI) databases: Bouygues I, Saint Gobain III, Stora Enso, Telefonica, and Vivendi. In the crisis period and ignoring funding and trading costs, we find two persistent negative bases less, for the four databases, than the ones reported in Panel B of Table 3: Edison and Telecom Italia II.

\subsubsection{Trade size analysis}

We employ CDSs with a notional equal to $€_{500,000}$ and assume that the strategy stops if the total investment in a given bond exceeds $25 \%$ of the bond's issued amount or if the total expected future losses exceed $€_{25} 5,000$. The reason for using this notional is to guarantee a substantial number of investments to test the existence of persistent anomalies in credit markets. However, as in some execution platforms for CDSs the minimum trade size is of $€_{1}$ million, we repeat the analysis employing CDSs of this notional value and increasing the barrier of losses to $€_{50,000}$. In the first subperiod we find one additional persistent mispricing: Bouygues I. In the crisis period and ignoring funding and trading costs, we find an additional mispricing: Union Fenosa.

\subsubsection{Nonconstant variance parameter}

Although the standard deviation parameter of the profits process, $\sigma$, was assumed to be constant, it could evolve as a GARCH process. We have repeated the analysis by letting the standard deviation parameter evolve as a GARCH. Results do not change significantly.

Note that it is easier to get into credit derivatives contracts than it is to get out of them. The CDSs' maturity is set at a given horizon and the investor can take the other side of the nearest maturity contract and build a book of offsetting positions, or try to sell the current contract. 


\subsubsection{Limit of losses analysis}

The barrier of 25,000 Euros for the total expected losses which determine the point at which the strategy stops could seem to be an arbitrary limit. For this reason, we repeated the test with barriers of 10,000 and 50,000 Euros and with no barrier under both UM and CM models. Results confirm that a barrier of 10,000 Euros seems too low given that it could lead to stopping the strategy prematurely. However, a barrier of 50,000 Euros and the absence of a barrier lead to the same results as using a limit of 25,000 Euros for both subperiods. Moreover, the absence of a barrier would involve a high risk for a given investor who tries to exploit such mispricing. 



\section{Conclusions}

The ongoing financial crisis and its possible consequences for the regulation of financial markets makes the study of the possible persistent mispricing in credit derivatives markets a topic of salient relevance.

We make four contributions to this important topic. First, we present the new MPR test of statistical arbitrage which allows for a more general structure in the innovations and which has lower Type I error and selects statistical arbitrage opportunities with lower downside risk than existing alternatives. Second, we apply the new test to a specific segment of the credit derivatives markets: CDS and ASP. Our third contribution relates to the appropriate way of testing for persistent mispricings. We focus primarily our analysis on the cases in which only long positions in CDSs and ASPs are needed. Fourth, we employ four different databases and find that, using the MPR test, during the period before the subprime crisis, in $29 \%$ of the cases the basis is persistently negative. On the other hand, during the crisis we find $17 \%$ cases with a persistent negative basis. Nevertheless, the persistent deviations between credit spreads, based on either long or short risk positions, are very frequent during the crisis. However after including reasonable estimations of transaction costs none of these mispricings is likely to provide profitable arbitrage opportunities. The empirical results suggest that arbitrageurs engaging in trading strategies to exploit mispricings or potential arbitrage opportunities detected by the previous versions of the statistical arbitrage test (but not detected by our test) are exposed unwittingly to significant downside risk that is even more extreme during the crisis period. This is an economically relevant difference between the MPR test and the JTTW and HJTWs test.

Looking forward, we expect more definite evidence on other arbitrage strategies as well as in other market segments. The new test and the procedure (long positions only) of this paper can also be applied to other financial markets. 



\section{References}

Acharya, V., Schaefer, S. and Zhang, Y. (2007). Liquidity risk and correlation risk: A clinical study of the General Motors and Ford Downgrade of May 2005. Working Paper, SSRN.

Affleck-Graves, J. and McDonald, B. (1989). "Nonnormalities and tests of asset pricing theories". Journal of Finance 44, pp. 889-908.

Aunon-Nerin, D., Cossin, D., Hricko, T. and Huang, Z. (2002). Exploring for the determinants of credit risk in credit default swap transaction data: Is fixed-income markets' information sufficient to evaluate credit risk?. Working paper, HEC-University of Lausanne and FAME.

Bajlum, C. and Larsen, T. (2007). Capital structure arbitrage: model choice and volatility calibration. Working Paper Series No. 230, Centre for Analytical Finance University of Aarhus.

Blanco, R., Brennan, S. and Marsh, I. W. (2005). "An empircal analysis of the dynamic relationship between investment grade bonds and credit default swaps". Journal of Finance 6o, pp. 2255-2281.

British Bankers' Association (2006). BBA Credit derivatives report 2006.

Bondarenko, O. (2003). "Statistical arbitrage and security prices". Review of Financial Studies, 16, 3, 875-919.

California Debt and Investment Advisory Commission (2007). "Understanding interest rate swap match \& pricing". CDIAC No. 06-11, January 2007.

Chen, R.-R., Cheng, X. and Liu, B. (2008). "Estimation and evaluation of the term structure of credit default swaps: An empirical study". Insurance: Mathematics and Economics, 43, pp. 339-349.

Cserna, B. and Imbierowicz, B. (2008). How efficient are credit default swap markets? An empirical study of capital structure arbitrage based on structural pricing models. Working Paper, Goethe University Frankfurt.

De Wit, J. (2006). Exploring the CDS-bond basis. Research series 200611-16. National Bank of Belgium.

Duarte, J., Longstaff, F. A. and Yu, F. (2007). "Risk and return in fixed income arbitrage: nickels in front of a steamroller". The Review of Financial Studies 20, pp. 769-811. 
Duffie, D. (1999). “Credit swap valuation”. Financial Analysts Journal 55, pp. 73-87.

Elizalde, A. and Doctor, S. (2009). The bond-CDS funding basis. J. P. Morgan European Credit Derivatives Research.

Elizalde, A., Doctor, S. and Saltuk, Y. (2009). Bond-CDS basis handbook. J. P. Morgan European Credit Derivatives Research.

Engle, R. F. and Granger, C. W. J. (1987). "Co-integration and error correction: Representation, estimation, and testing”. Econometrica 55, pp. 251-276.

Felsenheimer, J. (2004). CDS: Mechanism, pricing and application. HVB Global Markets Research, 2 June 2004.

Forte, S. and Peña, J. I. (2009). "Credit spreads: theory and evidence about the information content of stocks, bonds and CDSs”. Journal of Banking and Finance, 33, pp. 2013-2025.

Francis, C., Kakodkar, A. and Martin, B. (2003). Credit derivative handbook 2003. A guide to products, valuation, strategies and risks. Merrill Lynch Global Securities Research and Economics Group, April.

Fulop, A. and Lescourret, L. (2007). An analysis of intra-daily patterns on the CDS market. Working Paper, ESSEC Business School.

Hogan, S., Jarrow, R. A., Teo, M. and Warachka, M. (2004). "Testing market efficiency using statistical arbitrage with applications to momentum and value strategies". Journal of Financial Economics 73, pp. 525-565.

Hull, J., Predescu, M. and White, A. (2004). "The relationship between credit default swap spreads, bond yields, and credit rating announcements". Journal of Banking and Finance 28, pp. 2789-2811.

Jankowitsch, R., Pullirsch, R. and Veža, T. (2008). "The delivery option in credit default swaps". Journal of Banking and Finance 32, pp. 1269-1285.

Jarrow, R. A., Teo, M., Tse, Y. K. and Warachka, M. (2007). Statistical arbitrage and market efficiency: Enhanced theory, robust tests and further applications. Working Paper Series, Singapore Management University.

Jarrow, R., Li, H. and Ye, X. (2009). Exploring statistical arbitrage opportunities in the term structure of CDS spreads. Working Paper.

Levin, A., Perli, R. and Zakrajšek, E. (2005). "The determinants of market frictions in the corporate market". Computing in Economics and Finance 2005 379, Society for Computational Economics.

Lo, A. W. and Mackinlay, C. A. (1988). "Stock market do not follow random walks: Evidence from a simple specification test". Review of Financial Studies 1, pp. 41-66.

Longstaff, F. A, Mithal, S. and Neis, E. (2005). "Corporate yield spreads: Default risk or liquidity? New evidence from the credit default swap market". Journal of Finance 6o, pp. $2213-2253$. 
Mayordomo, S., Peña, J. I. and Romo, J. (2011). "The effect of liquidity on the price discovery process in credit derivatives markets in times of financial distress". The European Journal of Finance, forthcoming.

Mengle, D. (2007). "Credit derivatives: an overview". Economic Review, Federal Reserve Bank of Atlanta, issue Q4, pp. 1-24.

Nashikkar, A. J., Subrahmanyam, M. G. and Mahanti, S. (2009). Limited arbitrage and liquidity in the market for credit risk. NYU Working Paper No. FIN-o8-o11.

Nashikkar, A. J. and Subrahmanyam, M. G. (2007). Latent liquidity and corporate bond yield spreads. NYU Working Paper No. FIN-07-013.

Politis, D. N. and Romano, J. P. (1994). "The stationary bootstrap". Journal of the American Statistical Association 89, pp. 1303-1313.

Politis, D. N., Romano, J. P. and Wolf, M. (1995). Subsampling for nonstationary time series. Technical Report no. 483, Department of Statistics, Stanford University.

Politis, D. N., Romano, J. P. and Wolf, M. (1997). "Subsampling for heteroskedastic time series". Journal of Econometrics 81, pp. 281-317.

Politis, D. N., Romano, J. P. and Wolf, M. (1999a). Subsampling. Springer Series in Statistics. New York: Springer.

Politis, D. N., Romano, J. P. and Wolf, M. (1999b). "Subsampling intervals in autoregressive models with linear time trend”. Econometrica 69, pp. 1283-1314.

Predescu, M. (2006). The performance of structural models of default for firms with liquid CDS spreads. Working Paper, Rotman School of Management, University of Toronto.

Saita, L. (2006). The puzzling price of corporate default risk. Working paper, Standford Graduate School of Business.

Schonbucher, P. J. (2003). Credit derivatives pricing models: Models, pricing, implementation. Wiley Finance, New York.

Shiller, R. J. and Perron, P. (1985). "Testing the random walk hypothesis: Power versus frequency of observation”. Economic Letters 18, pp. 381-386.

Trapp, M. (2009). Trading the bond-CDS basis - The role of credit risk and liquidity. Working Paper No. o9-16. Centre for Financial Research.

Yu, F. (2006). "How profitable is capital structure arbitrage?". Financial Analysts Journal 62, pp. 47-62.

Zhu, H. (2006). "An empirical comparison of credit spreads between the bond market and the credit default swap market". Journal of Financial Services Research 29, pp. 211-235. 


